\section{Consenso Mexicano para la prescripción de inmunoglobulina $G$ como tratamiento de reemplazo e inmunomodulación}

Francisco Javier Espinosa-Rosales, ${ }^{1}$ Adolfina Bergés-García, ${ }^{2}$ Irma Alejandra Coronado-Zarco, ${ }^{3}$ Guillermo Dávila-Gutiérrez, ${ }^{4}$ Enrique Faugier-Fuentes, ${ }^{5}$ Jorge Alberto García-Campos, ${ }^{6}$ Saúl Oswaldo Lugo-Reyes, ${ }^{7}$ Carlos MartínezMurillo, ${ }^{8}$ María Dolores Mogica-Martínez, ${ }^{9}$ Nora Hilda Segura-Méndez, ${ }^{10}$ Mónica Edith Salmerón-Mercado, ${ }^{11}$ Aidé Tamara Staines-Boone, ${ }^{12}$ Edwin Steven Vargas-Cañas, ${ }^{13}$ Marco Antonio Yamazaki-Nakashimada ${ }^{14}$

Resumen

INTRODUCCIÓN: La disponibilidad y comercialización de la inmunoglobulina $\mathrm{G}$ humana ha modificado el curso y pronóstico de diversas enfermedades. Hoy en día representa el tratamiento de primera línea para al menos 10 enfermedades y de segunda línea, empírico o de indicación compasiva en otras alteraciones. La mayor parte de estas enfermedades son excepcionales (afectan a menos de 1 de cada 2000 individuos), por lo que la generación de evidencia robusta derivada de ensayos clínicos aleatorizados y controlados no es común.

OBJETIVO: desarrollar Elaborar o Emitir un Consenso Mexicano para la prescripción de Inmunoglobulina G Humana como tratamiento de reemplazo e inmunomodulación con un enfoque de medicina basada en evidencias.

MATERIALES Y MÉTODOS: Se integró un grupo multidisciplinario de especialistas en diversas áreas de la medicina en México, con la finalidad de emitir un análisis crítico y sistematizado de la evidencia clínica disponible para la prescripción de la inmunoglobulina G humana. Se revisaron las bases de datos MEDLINE, EMBASE, BVS-LILACS, NGS, NICE, CENETEC, Imbiomed, TripDatabase y Medigraphic. Para el análisis de la información se utilizaron algoritmos con términos Medical Subject Headings (MeSH) o Descriptores en Ciencias de la Salud (DeCS) específicos para cada enfermedad, con la intención de identificar guías de práctica clínica u otro tipo de guías, revisiones sistemáticas, metanálisis, ensayos clínicos aleatorizados, estudios clínicos, estudios descriptivos u observacionales y análisis de costobeneficio. Para el estudio de la evidencia se organizaron ocho grupos de trabajo, de acuerdo con el campo de conocimiento y la experiencia de los especialistas. Se formularon preguntas clínicas con el constructo PICO, por su acrónimo en inglés: Patients (pacientes o población), Intervention (intervención de interés), Comparison (comparación con otra intervención) y Outcome (desenlace de interés). Después de discutir las evidencias correspondientes y responder las preguntas, se redactó un documento con declaraciones específicas por indicación y calidad de evidencia con el esquema GRADE. Las declaraciones fueron sometidas a evaluación y consenso por todo el grupo de trabajo y se elaboró un documento con el formato actual para validación externa por los principales representantes de las academias y los colegios de las áreas del conocimiento incluidas, para finalmente publicarlo como tratamiento de referencia en la prescripción de la inmunoglobulina G humana en México.
${ }^{1}$ Inmunólogo pediatra, Fundación Mexicana para Niñas y Niños con Inmunodeficiencias Primarias, Hospital Ángeles Lomas, Ciudad de México.

${ }^{2}$ Hematóloga pediatra, Centro Médico Nacional La Raza (IMSS), Ciudad de México.

${ }^{3}$ Pediatra neonatóloga, Instituto Nacional de Perinatología Isidro Espinosa de los Reyes, Ciudad de México.

${ }^{4}$ Neurólogo pediatra, Instituto Nacional de Pediatría, Ciudad de México.

${ }^{5}$ Reumatólogo pediatra, profesor adjunto de Reumatología Pediátrica, Hospital Infantil de México Federico Gómez (SSA), Ciudad de México.

${ }^{6}$ Infectólogo, Unidad Médica de Alta Especialidad, Centro Médico del Noreste 25 (IMSS), Monterrey, Nuevo León.

${ }^{7}$ Investigador en Ciencias Médicas, Unidad de Investigación en Inmunodeficiencias del Instituto Nacional de Pediatría, Ciudad de México.

${ }^{8}$ Coordinador de la Clínica de Hemostasia y Trombosis, Hospital General de México Dr. Eduardo Liceaga. ${ }^{9}$ Inmunóloga y alergóloga, Centro Médico Nacional La Raza (IMSS), Ciudad de México.

${ }^{10}$ Inmunóloga y alergóloga, Centro Médico Nacional Siglo XXI (IMSS), Ciudad de México.

${ }^{11}$ Neuróloga, Hospital General de Occidente (IMSS), Guadalajara, Jalisco.

12 Inmunóloga y alergóloga pediatra, servicio de Inmunología de la Unidad Médica de Alta Especialidad, Centro Médico del Noreste 25 (IMSS), Monterrey, Nuevo León.

${ }^{13}$ Jefe de la Clínica de Nervio y Músculo, Instituto Nacional de Neurología, Ciudad de México.

${ }^{14}$ Inmunólogo y alergólogo pediatra, adscrito al servicio de Inmunología, Instituto Nacional de Pediatría, Ciudad de México.

Avales

Colegio Mexicano de Pediatras Especialistas en Inmunología Clínica y Alergia; Consejo Nacional de Inmunología Clínica y Alergia; Academia Mexicana de Neurología; Colegio Mexicano de Inmunología Clínica y Alergia; AMEH-Agrupación Mexicana para el Estudio de la Hematología.

Recibido: 19 de septiembre 2017

Aceptado: 14 de febrero 2018

Correspondencia

Francisco Javier Espinosa Rosales espinosa_francisco@yahoo.com.mx

Este artículo debe citarse como Espinosa-Rosales FJ, Bergés-García A, CoronadoZarco IA, Dávila-Gutiérrez G, Faugier-Fuentes E, García-Campos JA et al. Consenso Mexicano para la prescripción de inmunoglobulina $\mathrm{G}$ como tratamiento de reemplazo e inmunomodulación. Acta Pediatr Mex. 2018;39(2):134-171. 
CONCLUSIONES: La integración del consenso representa un esfuerzo en aras de proporcionar a los clínicos de instituciones de segundo y tercer nivel de atención en salud de México. Además de proporciona un instrumento validado para la prescripción correcta de inmunoglobulina G humana como tratamiento de reemplazo e inmunomodulación. Este documento debe actualizarse de manera continua, debido al activo campo de investigación clínica en diferentes aplicaciones de la medicina.

PALABRAS CLAVE: México; consenso; inmunoglobulina G, gammaglobulinas, inmunomodulación.

Acta Pediatr Mex. 2018 mar;39(2):134-171.

\section{Mexican consensus for the use of immunoglobulin $\mathrm{G}$ as replacement and immunomodulation treatment.}

Francisco Javier Espinosa-Rosales, ${ }^{1}$ Adolfina Bergés-García, ${ }^{2}$ Irma Alejandra Coronado-Zarco, ${ }^{3}$ Guillermo Dávila-Gutiérrez, ${ }^{4}$ Enrique Faugier-Fuentes, ${ }^{5}$ Jorge Alberto García-Campos, ${ }^{6}$ Saúl Oswaldo Lugo-Reyes, ${ }^{7}$ Carlos MartínezMurillo, ${ }^{8}$ María Dolores Mogica-Martínez, ${ }^{9}$ Nora Hilda Segura-Méndez, ${ }^{10}$ Mónica Edith Salmerón-Mercado, ${ }^{11}$ Aidé Tamara Staines-Boone, ${ }^{12}$ Edwin Steven Vargas-Cañas, ${ }^{13}$ Marco Antonio Yamazaki-Nakashimada ${ }^{14}$

\begin{abstract}
BACKGROUND: The availability, licensing and commercialization of human immunoglobulin G (IG) as a therapeutic product has drastically changed the course of several diseases. Currently IG represents first line therapy for at least 10 different diseases, and is used as off-label in many other conditions. The majority of such conditions are rare diseases (i.e. affecting $<1$ in 2,000 individuals), which imposes a considerable obstacle for the generation of robust clinical evidence from randomized clinical trials.
\end{abstract}

OBJECTIVE: To develop evidence-based clinical guidelines for the use of IG as replacement or immunomodulation therapy in our country.

MATERIAL AND METHODS: We conformed a group of several clinical experts from different specialties (work-group) to develop a critical and systematic analysis of the current evidence for the different uses of IG. We carried systematic reviews through Medical Subject Headings $(\mathrm{MeSH})$ terms and the Spanish equivalent "Descriptores en Ciencias de la Salud (DeCS)" specific for each clinical condition and looking for clinical practice guidelines, other types of guidelines, systematic reviews, meta-analysis, randomized clinical trials, non-randomized clinical trials, descriptive, observational and economic studies. We used the PICO construct whenever possible using the following databases: MEDLINE, EMBASE, BVS/LILACS, NGS, NICE, CENETEC, Imbiomed, TripDatabase, and Medigraphic. We organized 8 smaller specialty-specific groups to study corresponding evidence within their área of expertise and answer the clinical questions and write specific recommendations to make a draft. Such document was discussed in a

\section{Correspondencia}

Francisco Javier Espinosa Rosales espinosa_francisco@yahoo.com.mx
${ }^{1}$ Inmunólogo pediatra, Fundación Mexicana para Niñas y Niños con Inmunodeficiencias Primarias, Hospital Ángeles Lomas, Ciudad de México.

${ }^{2}$ Hematóloga pediatra, Centro Médico Nacional La Raza (IMSS), Ciudad de México. ${ }^{3}$ Pediatra neonatóloga, Instituto Nacional de Perinatología Isidro Espinosa de los Reyes, Ciudad de México.

${ }^{4}$ Neurólogo pediatra, Instituto Nacional de Pediatría, Ciudad de México.

${ }^{5}$ Reumatólogo pediatra, profesor adjunto de Reumatología Pediátrica, Hospital Infantil de México Federico Gómez (SSA), Ciudad de México.

${ }^{6}$ Infectólogo, Unidad Médica de Alta Especialidad, Centro Médico del Noreste 25 (IMSS), Monterrey, Nuevo León.

${ }^{7}$ Investigador en Ciencias Médicas, Unidad de Investigación en Inmunodeficiencias del Instituto Nacional de Pediatría, Ciudad de México.

${ }^{8}$ Coordinador de la Clínica de Hemostasia y Trombosis, Hospital General de México Dr. Eduardo Liceaga.

${ }^{9}$ Inmunóloga y alergóloga, Centro Médico Nacional La Raza (IMSS), Ciudad de México.

${ }^{10}$ Inmunóloga y alergóloga, Centro Médico Nacional Siglo XXI (IMSS), Ciudad de México. ${ }^{11}$ Neuróloga, Hospital General de Occidente (IMSS), Guadalajara, Jalisco.

${ }^{12}$ Inmunóloga y alergóloga pediatra, servicio de Inmunología de la Unidad Médica de Alta Especialidad, Centro Médico del Noreste 25 (IMSS), Monterrey, Nuevo León.

${ }^{13}$ Jefe de la Clínica de Nervio y Músculo, Instituto Nacional de Neurología, Ciudad de México.

${ }^{14}$ Inmunólogo y alergólogo pediatra, adscrito al servicio de Inmunología, Instituto Nacional de Pediatría, Ciudad de México.

Avales

Colegio Mexicano de Pediatras Especialistas en Inmunología Clínica y Alergia; Consejo Nacional de Inmunología Clínica y Alergia; Academia Mexicana de Neurología; Colegio Mexicano de Inmunología Clínica y Alergia; AMEH-Agrupación Mexicana para el Estudio de la Hematología. 
plenary session to agree a final document which was then submitted to external validation by the major representatives of the academia in our country. Finally, we wrote this document as a reference for clinicians regarding the therapeutic uses of IG in our country.

CONCLUSIONS: We see this document as an instrument to allow clinicians in the second and third level of health care of our country to correctly use IG as replacement and/or immune-modulation. Therapeutic use of IG is an active area of clinical research; this document shall be reviewed, modified and enriched accordingly and in a timely-manner.

KEYWORDS: Mexico; consensus; immunoglobulin G; gammaGlobulins; immunomodulation
Correspondence

Francisco Javier Espinosa Rosales espinosa_francisco@yahoo.com.mx

\section{INTRODUCCIÓN}

Las preparaciones de inmunoglobulina G humana disponibles comercialmente se obtienen de muestras de plasma de más de 1000 donadores de sangre. Esas preparaciones contienen entre 95 y $98 \%$ de moléculas de IgG monoméricas y elementos traza de $\lg \mathrm{A}$, IgM, entre otras proteínas plasmáticas. ${ }^{1}$

La IgG fue administrada por primera vez con fines terapéuticos por vía subcutánea en un paciente con agammaglobulinemia e infecciones de repetición, en quien se demostró su efectividad como tratamiento de reemplazo. ${ }^{2}$ Años después, con los adelantos en los métodos para fraccionar el plasma y purificar la lgG, se obtuvieron las primeras preparaciones disponibles para administración por vía intravenosa. ${ }^{1}$ En 1981 se publicó un estudio de 7 pacientes con púrpura trombocitopénica crónica y 6 con púrpura trombocitopénica idiopática aguda, en quienes se incrementaron sus concentraciones de plaquetas después del tratamiento con dosis altas de IgG por vía intravenosa y de esta forma se abrió la posibilidad de prescribirla para el tratamiento de afecciones autoinmunitarias e inflamatorias. ${ }^{3}$

Después del desarrollo inicial del método de fraccionamiento de plasma humano, por el profesor Edwin Cohn a principios del decenio de 1940, además de los avances científicos y tecnológicos, se han incorporado múltiples mejoras en el proceso industrial de la $\lg G$ y de esta forma han permitido obtener productos con mayor eficacia clínica, cada vez más puros, estables y seguros. ${ }^{4}$ La Figura 1 muestra los acontecimientos iniciales en la indicación de la lgG y la evolución de las formulaciones comercialmente disponibles.

El Consejo de Salubridad General, dependiente de la Secretaría de Salud de México, en su cuadro básico de medicamentos ha otorgado diversas claves para el registro de preparaciones de IgG para su administración por vía intravenosa (5 y $10 \%$ ) y subcutánea (16.5 y $20 \%$ ), en el tratamiento de reemplazo de pacientes con inmunodeficiencias primarias y secundarias. Además, el Consejo de Salubridad General tiene aprobada la prescripción de IgG por vía intravenosa como tratamiento de inmunomodulación en pacientes con púrpura trombocitopénica, enfermedad de Kawasaki, síndrome de Guillain-Barré y polineuropatía desmielinizante inflamatoria crónica. ${ }^{5}$

La Agencia Reguladora de Medicamentos y Alimentos de Estados Unidos (Food and Drug Administration [FDA]) aprobó la prescripción de IgG por vía intravenosa para el tratamiento de inmunodeficiencias primarias, púrpura trombocitopénica autoinmunitaria, enfermedad de Kawasaki, trasplante de células progenitoras hematopoyéticas, leucemia linfocítica crónica 
Espinosa-Rosales FJ et al. Inmunoglobulina G para reemplazo e inmunomodulación

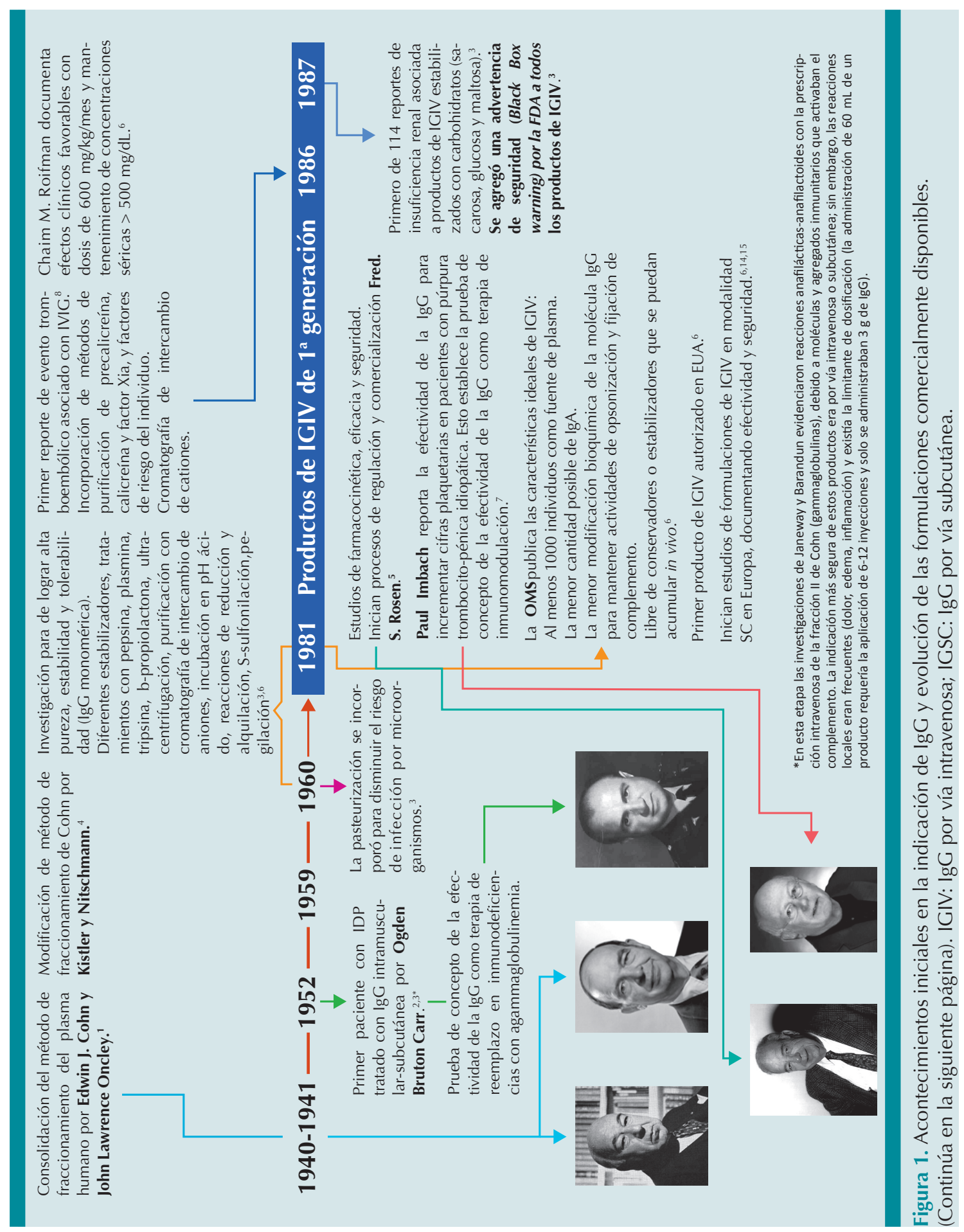




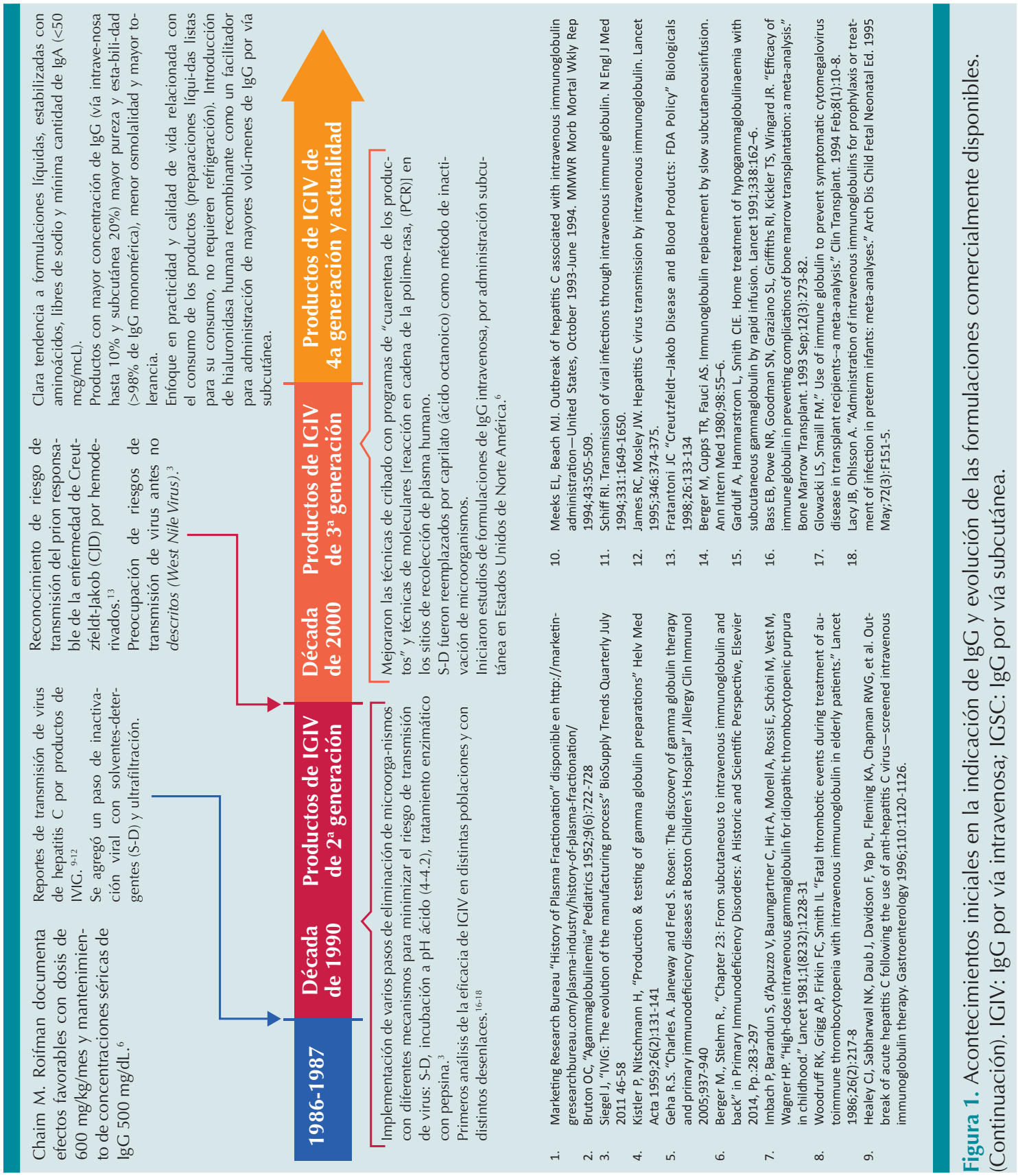


de células B, enfermedad por virus de inmunodeficiencia humana en niños, neuropatía motora multifocal y polineuropatía inflamatoria desmielinizante crónica. Incluso aprobó la indicación de IgG por vía subcutánea en el tratamiento de inmunodeficiencias primarias humorales en niños y adultos y desde el año 2014 certificó la administración por vía subcutánea con hialuronidasa humana recombinante $(\mathrm{rhH})$ para el tratamiento de inmunodeficiencias primarias humorales en adultos. ${ }^{6}$

En el Cuadro 1 se muestran los productos de IgG aprobados por la COFEPRIS y sus características más importantes.

Aunque en la actualidad la IgG se prescribe para el tratamiento de diversos padecimientos inflamatorios y autoinmunitarios, en prácticamente todas las especialidades de la medicina no existe evidencia sólida que respalde de su eficacia. Por lo general, su indicación se establece con base en el conocimiento de inmunología básica y fisiopatología de las enfermedades autoinmunitarias, además de las dosis altas de IgG en diferentes receptores y células que generan un efecto "regulador", evaluadas en series o reportes de casos clínicos relacionados con sus beneficio. Esto obedece a que representan padecimientos de muy baja prevalencia, lo que hace sumamente difícil contar con ensayos clínicos controlados.

El objetivo de este estudio fue elaborar o emitir un consenso mexicano para la prescripción de inmunoglobulina G humana como tratamiento de reemplazo e inmunomodulación, con un enfoque de medicina basada en evidencias. Este documento pretende guiar al clínico en la toma de decisiones y orientar a las autoridades sanitarias para entender mejor la función de las preparaciones de $\lg G$ en el contexto actual de las instituciones de salud.

\section{MATERIALES Y MÉTODOS}

Se integró un grupo multidisciplinario de especialistas en diversos campos de la medicina en México (hematología, infectología, inmunología clínica, neonatología, neurología y reumatología), con la finalidad de emitir un consenso en la prescripción de inmunoglobulina G humana. Se realizó la búsqueda de revisiones sistemáticas en las bases de datos: MEDLINE, EMBASE, BVS-LILACS, NGS, NICE, CENETEC, Imbiomed, TripDatabase y Medigraphic. Para el análisis de los datos se utilizaron algoritmos de búsqueda con términos (Medical Subject Headings, MeSH) o Descriptores en Ciencias de la Salud (DeCS) específicos para cada enfermedad clínica, con la intención de identificar guías de práctica clínica y otros tipos de guías, artículos de revisión sistemáticos, metanálisis, ensayos clínicos aleatorizados, casos clínicos, estudios descriptivos u observacionales y evaluaciones de costobeneficio. Solo se incluyeron publicaciones en idioma español e inglés, de 1980 a la fecha. Para el estudio de la evidencia se organizaron ocho grupos de trabajo, según el campo de conocimiento y experiencia de los especialistas (inmunodeficiencias primarias y secundarias; enfermedades hematológicas, neurológicas e infecciosas; alteraciones neonatales, indicaciones relacionadas con trasplante e indicaciones misceláneas) y de esta manera formularon preguntas clínicas con el constructo PICO, por su acrónimo en inglés: Patients (pacientes o población), Intervention (intervención de interés), Comparison (comparación con otra intervención) y Outcome (desenlace de interés). ${ }^{7}$ Cada grupo de trabajo realizó un análisis crítico y sistematizado de la calidad de la evidencia clínica disponible para las diferentes indicaciones de la IgG. Después de discutir las evidencias correspondientes y responder las preguntas formuladas, se redactó un documento con declaraciones específicas por indicación y calidad de su evidencia, de acuerdo con el sistema GRADE (Grading of Recommendations Assessment, Development, 







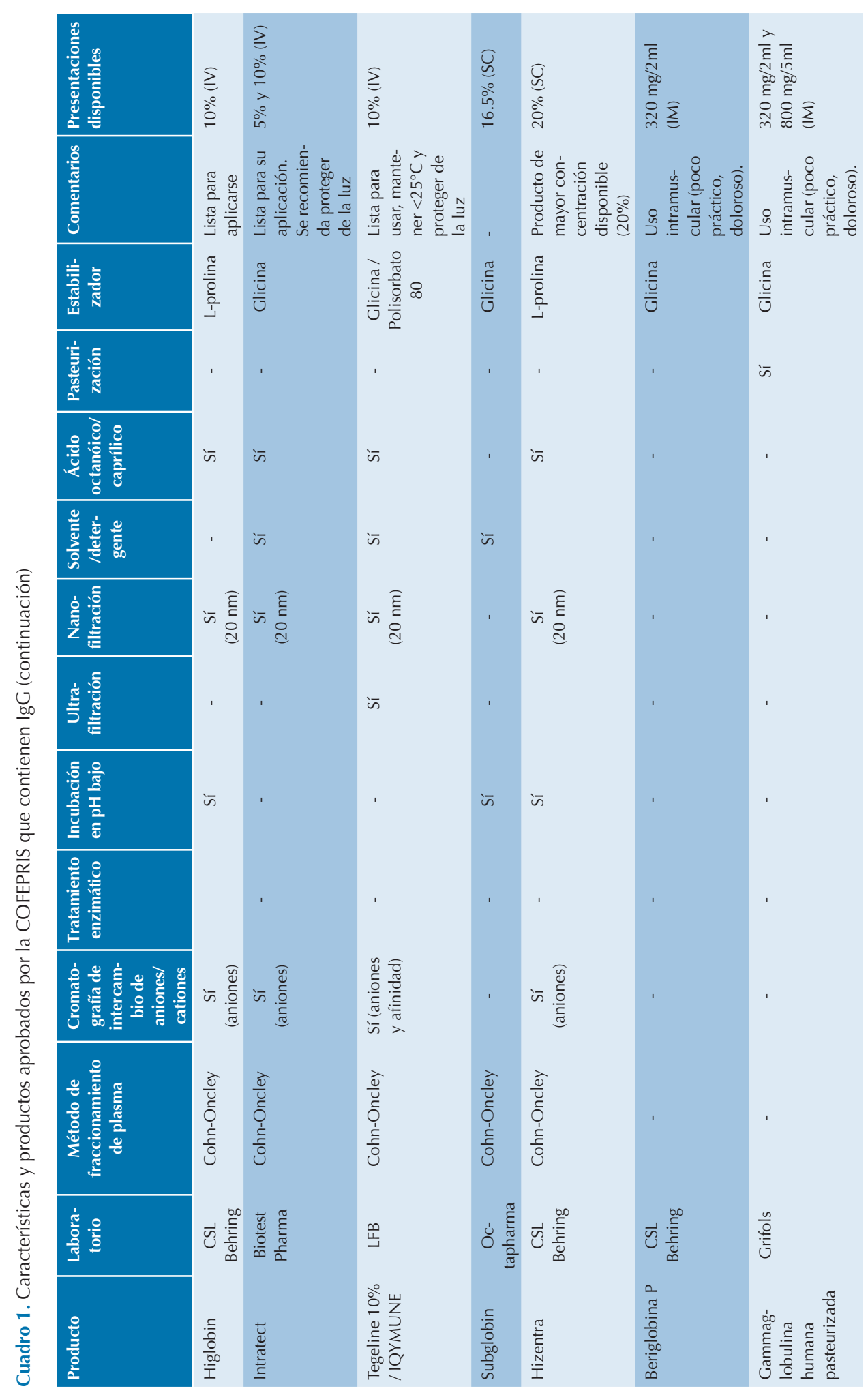


and Evaluation), ${ }^{8}$ que evalúa la calidad de la evidencia y la define como "alta" cuando es poco probable que investigaciones futuras cambien la estimación del efecto; "moderadamente alta" cuando al realizar investigaciones adicionales repercuta en un cambio relacionado con algún efecto estimado; "baja" cuando es probable que cambie la percepción del efecto al realizar más investigaciones y "muy baja" cuando cualquier estimación del efecto es incierta. El sistema GRADE también califica el nivel de evidencia en $A, B, C$ y D para calidad alta, moderada, baja y muy baja, respectivamente. La fuerza o grado de recomendación se califica de manera binaria como: 1 para recomendación fuerte a favor de la intervención y 2 para débil a favor de la intervención; 2 para débil en contra de la intervención y 1 para fuerte en contra de la intervención (Cuadro 2). ${ }^{9}$

Cuadro 2. Niveles de evidencia y fuerza de recomendación

\begin{tabular}{|l|c|c|c|}
\hline Calidad & Código & $\begin{array}{c}\text { Fuerza de la } \\
\text { recomendación }\end{array}$ & Código \\
\hline Alta & A & $\begin{array}{c}\text { Fuerte a favor de la } \\
\text { intervención }\end{array}$ & 1 \\
\hline Moderada & B & $\begin{array}{c}\text { Débil a favor de la } \\
\text { intervención }\end{array}$ & 2 \\
\hline Baja & C & $\begin{array}{c}\text { Débil en contra de } \\
\text { la intervención }\end{array}$ & 2 \\
\hline Muy baja & D & $\begin{array}{c}\text { Fuerte en contra de } \\
\text { la intervención }\end{array}$ & 1 \\
\hline
\end{tabular}

Adaptado de Oñate-Ocaña LF, Ochoa-Carrillo FJ. Sistema GRADE para clasificar nivel de evidencia y grado de las recomendaciones para la elaboración de guías de buena práctica clínica. Cir Ciruj 2009;77:417-419.

En la reunión presencial final y de manera plenaria se discutieron temas de controversia y se conformaron las recomendaciones finales en dos formatos: un documento que explica las recomendaciones y un cuadro de síntesis de las mismas (Cuadro 3). Las guías se sometieron a validación externa por los principales representantes de las academias y los colegios de las áreas de conocimiento incluidas.

\section{TRATAMIENTO DE REEMPLAZO}

El tratamiento de reemplazo con IgG proporciona anticuerpos como moléculas monoméricas policlonales, poliespecíficas con un perfil fisiológico de subclases (IgG1-4) y con actividad biológica completa de sus regiones Fab (fracción de unión al antígeno o antigen-binding fraction) y Fc (fracción cristalizable), para permitir la unión con el antígeno, neutralización de toxinas, opsonización, facilitación de fagocitosis, activación de inmunorreceptores en neutrófilos y macrófagos, y activación del complemento. El tratamiento de reemplazo tiene como objetivo bioquímico normalizar las concentraciones séricas de lgG y clínico de disminuir la frecuencia y gravedad de los procesos infecciosos. La FDA define como "eficaz" al producto capaz disminuir el número de infecciones bacterianas graves a menos de 1 evento por año-paciente. ${ }^{10}$

\section{R. La administración de IgG como tratamiento de reemplazo en pacientes con inmunodefi- ciencias primarias puede administrase por vía intravenosa o subcutánea, pues su eficacia es comparable/similar (GRADE B1). ${ }^{11-17}$}

\section{R. La administración de IgG como tratamiento} de reemplazo consiste en dosis de 400-600 mg/ kg por vía intravenosa cada 3 a 4 semanas (GRADE B1) o 100-150 mg/kg por vía subcutánea por semana, incluso de $\mathbf{2 0 0 - 3 0 0 ~} \mathrm{mg} / \mathrm{kg}$ cada 2 semanas (GRADE B1). ${ }^{11-17}$

\section{R. No existen diferencias significativas en la eficacia de diversas formulaciones de IgG dis- ponibles comercialmente para su aplicación intravenosa o subcutánea (GRADE B1). ${ }^{18}$}

El tratamiento de reemplazo puede ser una estrategia permanente o temporal, según su indicación en cada paciente. 
Espinosa-Rosales FJ et al. Inmunoglobulina G para reemplazo e inmunomodulación

Cuadro 3. Nivel de evidencia y fuerza de recomendación por afección y condición clínica (continúa en la siguiente página)

\begin{tabular}{|c|c|c|c|}
\hline \multicolumn{4}{|l|}{ Inmunodeficiencias primarias } \\
\hline $\begin{array}{l}\text { Afección } \\
\text { Condición clínica }\end{array}$ & $\begin{array}{l}\text { Nivel de } \\
\text { evidencia }\end{array}$ & $\begin{array}{l}\text { Fuerza de la } \\
\text { recomendación }\end{array}$ & Recomendación \\
\hline Agammaglobulinemia & B & 1 & Primera línea \\
\hline Inmunodeficiencia común variable & B & 1 & Primera línea \\
\hline Síndrome de híper-IgM & $\mathrm{C}$ & 1 & Primera línea \\
\hline Hipogammaglobulinemia transitoria de la infancia & $\mathrm{C}$ & 2 & Individualizar \\
\hline Deficiencia específica de anticuerpos & $\mathrm{C}$ & 2 & Individualizar \\
\hline Deficiencia selectiva de IgA & & & Condicionada \\
\hline Deficiencia selectiva de subclases de $\lg G$ & $\mathrm{C}$ & 2 & Condicionada \\
\hline $\begin{array}{l}\text { Síndrome linfoproliferativo con } \\
\text { hipogammaglobulinemia }\end{array}$ & B & 1 & Primera línea \\
\hline Inmunodeficiencia combinada grave & B & 1 & Primera línea \\
\hline $\begin{array}{l}\text { Síndrome de híper lgE autosómico dominante y } \\
\text { autosómico recesivo }\end{array}$ & B & 1 & Primera línea \\
\hline Síndrome Wiskott-Aldrich & B & 1 & Primera línea \\
\hline Defectos de la vía NFkB & B & 2 & Individualizar \\
\hline Síndrome WHIM & B & 1 & Primera línea \\
\hline \multicolumn{4}{|c|}{ Administración de IgG por vía intravenosa en pacientes que reciben trasplante } \\
\hline Prevención, infecciones postrasplante & A & 1 & No \\
\hline $\begin{array}{l}\text { Profilaxis post postrasplante de células progenitras } \\
\text { hematopoyéticas (rutinaria) }\end{array}$ & B & 1 & No \\
\hline $\begin{array}{l}\text { Profilaxis post postrasplante de células progenitras } \\
\text { hematopoyéticas en hipogammaglobulinemia } \\
\text { mieloma, leucemia linfocítica crónica, injerto contra } \\
\text { huésped }\end{array}$ & A & 1 & Primera línea \\
\hline Prevención y tratamiento injerto contra huésped & B & 1 & Individualizar \\
\hline $\begin{array}{l}\text { Neumonitis por CMV en trasplante de células } \\
\text { progenitras hematopoyéticas }\end{array}$ & A & 1 & Sí, en combinación con ganciclovir \\
\hline Trasplante órgano sólido desensibilización & $\mathrm{C}$ & 2 & Individualizar \\
\hline $\begin{array}{l}\text { Trasplante órgano sólido profilaxis injerto contra } \\
\text { huésped agudo }\end{array}$ & B & 1 & Primera línea \\
\hline $\begin{array}{l}\text { Enfermedad linfoproliferativa postrasplante } \\
\text { por virus Epstein Barr }\end{array}$ & $\mathrm{D}$ & 2 & Individualizar \\
\hline \multicolumn{4}{|c|}{ Administración de IgG por vía intravenosa en neonatología } \\
\hline Sepsis neonatal & A & 1 & No \\
\hline Enfermedad hemolítica & $\mathrm{C}$ & 2 & Individualizar \\
\hline Trombocitopenia aloinmunitaria & $\mathrm{C}$ & 2 & Individualizar \\
\hline $\begin{array}{l}\text { IgG intravenosa durante el embarazo en enfermedad } \\
\text { hemolítica }\end{array}$ & $\mathrm{C}$ & 2 & Individualizar \\
\hline Trombocitopenia prenatal & $\mathrm{C}$ & 2 & Individualizar \\
\hline
\end{tabular}


Cuadro 3. Nivel de evidencia y fuerza de recomendación por afección y condición clínica (continua la siguiente página)

\begin{tabular}{|c|c|c|c|}
\hline \multicolumn{4}{|l|}{ Inmunodeficiencias primarias } \\
\hline $\begin{array}{l}\text { Afección } \\
\text { Condición clínica }\end{array}$ & $\begin{array}{l}\text { Nivel de } \\
\text { evidencia }\end{array}$ & $\begin{array}{l}\text { Fuerza de la } \\
\text { recomendación }\end{array}$ & Recomendación \\
\hline \multicolumn{4}{|l|}{ Misceláneas } \\
\hline Sepsis (pediatría-adultos) & A & 1 & Individualizar \\
\hline Choque tóxico & $\mathrm{C}$ & 2 & Individualizar \\
\hline Colitis por C. difficile & C & 2 & Individualizar \\
\hline Aplasia pura de serie roja por Parvovirus B 19 & $\mathrm{C}$ & 2 & Individualizar \\
\hline Enfermedad de Kawasaki & A & 1 & primera línea \\
\hline \multicolumn{4}{|l|}{ Inmunodeficiencias secundarias } \\
\hline Mieloma múltiple & A & 2 & Condicionada \\
\hline Leucemia linfocítica crónica & A & 1 & Condicionada \\
\hline Enfermedades con pérdida de proteínas & $\mathrm{D}$ & 2 & Individualizar \\
\hline Hipogammaglobulinemia por antiepilépticos & $\mathrm{D}$ & 1 & Condicionada \\
\hline Hipogammaglobulinemia por rituximab & $\mathrm{C}$ & 1 & Individualizar \\
\hline Infección por VIH en niños & A & 2 & Individualizar \\
\hline \multicolumn{4}{|l|}{ Enfermedades autoinmunitarias } \\
\hline Púrpura trombocitopénica autoinmunitaria & A & 1 & Primera línea \\
\hline Púrpura postransfusional & $\mathrm{C}$ & 2 & Individualizar \\
\hline Neutropenia autoinmunitaria & $\mathrm{D}$ & 2 & No \\
\hline Anemia hemolítica autoinmunitaria & $\mathrm{D}$ & 2 & Individualizar \\
\hline Síndrome de Evans & $\mathrm{D}$ & 2 & Individualizar \\
\hline Polimiositis-dermatomiositis & B & 1 & Individualizar \\
\hline Miositis por cuerpos de inclusión & C & 2 & No \\
\hline Hemofilia adquirida & $\mathrm{C}$ & 2 & Individualizar \\
\hline Hemofagocitosis & $\mathrm{D}$ & 2 & Individualizar \\
\hline \multicolumn{4}{|l|}{ Enfermedades neurológicas } \\
\hline Síndrome de Guillain-Barré & A & 1 & Primera línea \\
\hline Polineuropatía crónica inflamatoria desmielinizante & A & 1 & Primera línea \\
\hline Neuropatía multifocal motora & A & 1 & Primera línea \\
\hline Neuropatía periférica & $\mathrm{D}$ & 2 & Individualizar \\
\hline Neuropatía desmielinizante paraproteinémica & $\mathrm{C}$ & 1 & Individualizar \\
\hline Encefalomielitis aguda diseminada & $\mathrm{D}$ & 2 & Segunda línea \\
\hline Neuromielitis óptica & $\mathrm{D}$ & 2 & Segunda línea \\
\hline $\begin{array}{l}\text { Síndrome opsoclono-mioclono o encefalopatía mio- } \\
\text { clónica infantil }\end{array}$ & $\mathrm{D}$ & 2 & Individualizar \\
\hline Síndrome de persona rígida & B & 1 & Primera línea \\
\hline Encefalitis límbica autoinmunitaria & C & 2 & Primera línea. \\
\hline Miastenia grave & A & 1 & Primera línea \\
\hline
\end{tabular}


Cuadro 3. Nivel de evidencia y fuerza de recomendación por afección y condición clínica (continuación)

\begin{tabular}{|c|c|c|c|}
\hline \multicolumn{4}{|l|}{ Inmunodeficiencias primarias } \\
\hline $\begin{array}{l}\text { Afección } \\
\text { Condición clínica }\end{array}$ & $\begin{array}{l}\text { Nivel de } \\
\text { evidencia }\end{array}$ & $\begin{array}{l}\text { Fuerza de la } \\
\text { recomendación }\end{array}$ & Recomendación \\
\hline Síndrome miasténico Lambert-Eaton & B & 2 & Individualizar \\
\hline Síndromes epilépticos y epilepsia infantil intratable & $\mathrm{D}$ & 2 & Individualizar \\
\hline Esclerosis múltiple & $\mathrm{C}$ & 2 & Segunda línea \\
\hline Esclerosis múltiple en mujer embarazada & $\mathrm{C}$ & 2 & Primera línea \\
\hline \multicolumn{4}{|l|}{ Enfermedades autoinmunitarias en pediatría } \\
\hline Artritis idiopática juvenil & C & 2 & Individualizar \\
\hline Lupus eritematoso sistémico & $\mathrm{C}$ & 2 & Condicionada \\
\hline Síndrome antifosfolípido catastrófico & $\mathrm{C}$ & 2 & Individualizar \\
\hline Dermatomiositis & $\mathrm{C}$ & 2 & Condicionada \\
\hline Vasculitis sistémicas & C & 2 & Individualizar \\
\hline Síndrome de activación de macrófagos & $\mathrm{C}$ & 2 & Individualizar \\
\hline
\end{tabular}

WHIM: Verrugas, hipogammaglobulinemia, infecciones de repetición y mielocatexis por sus siglas en inglés. EBV: virus Epstein-Barr; TCPH: trasplante de células progenitoras hematopoyéticas; LLC: leucemia linfocítica crónica. TOS: trasplante de órgano sólido. PB19: Parvovirus B19

R. El tratamiento de reemplazo con IgG de manera temporal está indicado por un período de 12 a 24 meses. Posteriormente se suspende su aplicación y se lleva a cabo la reevaluación del estado clínico del paciente y de la respuesta inmunitaria contra antígenos proteínicos, polisacáridos, o ambos, después de tres meses de la última dosis de IgG (GRADE D2). ${ }^{11,19-21}$

R. Antes de iniciar la administración de IgG debe establecerse el diagnóstico de inmunodeficiencia primaria, con la finalidad de justificar su indicación, además de la evaluación adicional por estudios de laboratorio como: biometría hemática completa, determinación de creatinina y pruebas de función hepática (GRADE D1). ${ }^{20,22-24}$

R. Los pacientes con inmunodeficiencia primaria en tratamiento de reemplazo con IgG deben evaluarse cada 3 a 6 meses, con énfasis en la frecuencia, tipo de infecciones y concentraciones séricas de IgG preinfusión. Los estudios adicionales deben individualizarse (GRADE D2). ${ }^{20,23,24}$
R. Los principales objetivos del tratamiento de reemplazo con IgG consisten en reducir la frecuencia y gravedad de las infecciones, prevenir el daño en órganos afectados y normalizar las concentraciones de IgG sérica conforme a la edad del paciente (GRADE D2). 20,22,25

\section{INMUNODEFICIENCIAS PRIMARIAS Y SECUNDARIAS}

Inmunodeficiencias primarias

Las inmunodeficiencias primarias incluyen más de 350 enfermedades hereditarias, principalmente causadas por defectos monogénicos que afectan el desarrollo, la función del sistema inmunológico, o ambos, y confirieren susceptibilidad a infecciones, inflamación, autoinmunidad y cáncer. ${ }^{26}$ Aproximadamente $85 \%$ de las inmunodeficiencias afectan el sistema inmunitario adaptativo humoral sin o con producción deficiente de anticuerpos. ${ }^{27} \mathrm{El}$ 
tratamiento de reemplazo con IgG por vía intravenosa o subcutánea ha demostrado eficacia y seguridad, por lo que representa el protocolo de primera línea para diversas inmunodeficiencias primarias. $^{28}$

Los principales tipos de inmunodeficiencias primarias relacionados con la prescripción de IgG incluyen:

a) Inmunodeficiencia con defecto primario de linfocitos B: agammaglobulinemia ligada al cromosoma $X$, agammaglobulinemias autosómicas recesivas, inmunodeficiencia común variable, defectos en el cambio de isotipo o de hipermutación somática, e hipogammaglobulinemia transitoria de la infancia. En este tipo de inmunodeficiencias existe nula o deficiente producción de anticuerpos, lo que provoca hipogammaglobulinemia (valor sérico $\leq 500 \mathrm{mg} / \mathrm{dL}$ en adultos o dos desviaciones estándar por debajo de los valores normales para la edad en niños y adultos) o agammaglobulinemia (ausencia de inmunoglobulinas séricas). ${ }^{26}$

La Academia Americana de Alergia, Asma e Inmunología (AAAAI) y la Sociedad Europea de Inmunodeficiencias (ESID, por sus siglas en inglés) consideran que la IgG beneficia, definitivamente, a este tipo de pacientes, por lo que el tratamiento debe iniciar al momento de establecer el diagnóstico. ${ }^{29-33} \mathrm{El}$ tratamiento de reemplazo con IgG disminuye la frecuencia y gravedad de las infecciones. ${ }^{34}$ Existe una correlación positiva entre la dosis de lgG administrada y la concentración de IgG sérica en los pacientes tratados por vía intravenosa y subcutánea. ${ }^{14}$ También se ha demostrado una correlación inversamente proporcional entre las concentraciones séricas de lgG y la frecuencia y gravedad de procesos infecciosos en estos pacientes. ${ }^{25}$

El tratamiento de reemplazo con IgG no muestra beneficio en la incidencia de malignidad o autoinmunidad.
R. Los pacientes con agammaglobulinemia deben recibir tratamiento de reemplazo con IgG de forma regular y no interrumpirlo desde el momento en que se establece el diagnóstico (GRADE B1). ${ }^{25,28}$

R. Las inmunodeficiencias con defectos primarios de células $B$ deben tratarse con dosis de $400-600 \mathrm{mg} / \mathrm{kg}$ de IgG por vía intravenosa


dosis de 100 a $150 \mathrm{mg} / \mathrm{kg}$ por vía subcutánea por semana, incluso 200 a $300 \mathrm{mg} / \mathrm{kg}$ cada 2 semanas (GRADE B1). ${ }^{14,16,38,39}$

R. La misma dosis mensual de IgG administrada por vía intravenosa puede aplicarse por vía subcutánea (GRADE B1). ${ }^{40}$

R. Las dosis de IgG por vía intravenosa o subcutánea deben ajustarse de acuerdo con el grado de hipogammaglobulinemia, gravedad de las infecciones y daño a órganos afectados (GRADE B1). ${ }^{22,35-37}$

R. La primera infusión de IgG intravenosa en pacientes con agamma-hipogammaglobulinemia que no han recibido tratamiento debe administrarse a una velocidad de 0.5 a $1 \mathrm{mg} /$ kg por minuto. Después de 15 minutos se incrementará la velocidad de 1.5 a $2.5 \mathrm{mg} / \mathrm{kg}$ por minuto. El aumento debe ser continuo, según la tolerancia, hasta alcanzar $4 \mathrm{mg} / \mathrm{kg}$ por minuto (GRADE B1). ${ }^{22,38,41}$

R. El tratamiento de reemplazo con IgG por vía subcutánea debe iniciar a una velocidad de infusión de 1-2 $\mathrm{mL} / \mathrm{min}(60-120 \mathrm{~mL} / \mathrm{h})$, con volumen máximo por sitio de $20-30 \mathrm{~mL}$. Incluso pueden utilizarse, al mismo tiempo, múltiples sitios de infusión (GRADE C2). ${ }^{14,6,38}$

R. Los pacientes con inmunodeficiencia común variable deben recibir tratamiento de reemplazo con IgG desde el momento del diagnóstico, independientemente del antecedente de infecciones graves, recurrentes, $o$ ambas. Es 
importante comprobar la producción deficiente de anticuerpos específicos antes iniciar el tratamiento con IgG (GRADE B1). ${ }^{11,22,42-48}$

R. Los pacientes con defectos en el cambio de isotipo o con defectos en la hipermutación somática deben recibir tratamiento de reemplazo con IgG (GRADE C1). ${ }^{22}$

R. En los pacientes con hipogammaglobulinemia transitoria de la infancia, con infecciones graves o procesos infecciosos febriles de difícil control (algunos autores consideran más de seis episodios al año), debe administrarse IgG. En estos pacientes debe reevaluarse su estado inmunológico luego de 6 y 12 meses postratamiento (GRADE C2). 19,22,28,49-51 $^{\text {(G) }}$

b) Inmunodeficiencias primarias con concentraciones normales de lgG total, pero con alteración significativa de la producción de anticuerpos específicos: inmunodeficiencia selectiva de anticuerpos contra antígenos polisacáridos, inmunodeficiencia por defecto de subclases de IgG, deficiencia de IgA relacionada con deficiencia de lgG2/lgG3 o con deficiencia selectiva de anticuerpos. Los pacientes con este tipo de inmunodeficiencias reportan concentraciones normales de IgG total; sin embargo, se encuentra disminuida la concentración sérica de algunas subclases de IgG, de IgA o IgG contra antígenos polisacáridos incluidos en la vacuna contra neumococo (conjugada hepta-, deca- o tridecavalente o no conjugada de 23 serotipos), lo que representa un factor de riesgo para infecciones frecuentes y graves.

R. Los pacientes con inmunodeficiencia selectiva de anticuerpos, con evidencia de infecciones recurrentes como: sinusitis, otitis media con alto riesgo de pérdida auditiva, neumonías, bronquiectasias, requerimiento de antibióticos por vía intravenosa o hipersensibilidad múltiple a los antibióticos que interfiere con los tratamientos deben recibir tratamiento de reemplazo con IgG (GRADE C2). ${ }^{11,20,22,50-52}$
R. Los pacientes con inmunodeficiencia específica de subclases IgG3, IgG4 e IgG2 deben recibir tratamiento de reemplazo con IgG solamente cuando la deficiencia se asocia con algún defecto específico de anticuerpos contra polisacáridos y quienes manifiestan infecciones recurrentes, graves, $o$ ambas, como las que se refieren en el defecto específico de producción de anticuerpos contra polisacáridos (GRADE C2). ${ }^{11,20}$

R. La deficiencia selectiva de IgA no supone indicación de tratamiento de reemplazo con IgG; sin embargo, cuando se asocia con inmunodeficiencia selectiva de anticuerpos, con o sin deficiencia de IgG2, puede considerarse la administración de IgG (GRADE D2).50,53,54

c) Inmunodeficiencia con alteración significativa de la producción de anticuerpos: inmunodeficiencia combinada grave (SCID, por sus siglas en inglés), síndrome de hiper-lgE (defectos de STAT3 y de DOCK8), síndrome de WiskottAldrich, síndromes linfoproliferativos con hipo- o disgammaglobulinemia, defectos en la vía del factor nuclear NF-KB, síndrome WHIM (verrugas, hipogammaglobulinemia, infecciones y mielocatexis, por sus siglas en inglés) y síndromes de hiper-IgM.

R. Los pacientes con sospecha o diagnóstico confirmado de inmunodeficiencia combinada grave, con o sin linfocitos $B$, deben recibir tratamiento de reemplazo con IgG de forma inmediata, y mantenerlo durante y después del trasplante de células hematopoyéticas, hasta asegurarse la reconstitución de linfocitos $T$ y normalizar la función de los linfocitos B (GRADE B1). ${ }^{11,22,55,56}$

R. En los pacientes con síndrome de hiper-IgE, en quienes se confirma la deficiencia de producción de anticuerpos específicos contra antígenos T-independientes, está indicado el tratamiento de reemplazo con IgG (GRADE B1). ${ }^{11,22,57-60}$ 
R. En los pacientes con síndrome Wiskott-Aldrich está indicado el tratamiento de reemplazo con IgG, pues supone una inmunodeficiencia típicamente asociada con producción inadecuada de anticuerpos específicos (se considera una inmunodeficiencia combinada). El tratamiento debe mantenerse hasta que el paciente reciba un trasplante de células hematopoyéticas y se compruebe la reconstitución de la función de las células $T$ y $B$. En estos pacientes, la prescripción de IgG ha disminuido la incidencia de infecciones (GRADE B1). ${ }^{11,22,61,62}$

R. En los pacientes con síndrome linfoproliferativo autoinmunitario con hipogammaglobulinemia, disgammaglobulinemia, $\mathrm{o}$ ambas, $\mathrm{e}$ infecciones, está indicado el tratamiento con IgG (GRADE B1). ${ }^{11,63,64}$

R. Los pacientes con defectos en la vía del factor de transcripción NF-_B con inmunodeficiencia deben recibir tratamiento de reemplazo con IgG (GRADE B2). Los pacientes con este tipo de inmunodeficiencia muestran elevada susceptibilidad para infecciones por neumococo y deficiente respuesta contra antígenos de polisacáridos. ${ }^{11,65,66}$

R. En los pacientes con síndrome WHIM (verrugas, hipogammaglobulinemia, infecciones y mielocatexis) está indicado el tratamiento de reemplazo con IgG (GRADE B1). ${ }^{11,22,67}$

R. Los pacientes con síndrome de hiper-IgM deben recibir tratamiento de reemplazo con IgG (GRADE C1). ${ }^{22}$

Recomendaciones adicionales para el tratamiento de inmunodeficiencias primarias

R. Los pacientes que reciben tratamiento de reemplazo con IgG por inmunodeficiencias primarias deben someterse al ajuste de dosis en caso de persistir con infecciones (más de tres infecciones moderadas al año), falla de medro o elevada pérdida de proteínas. En los pacientes con daño pulmonar grave (por ejemplo, bronquiectasias) debe incrementarse la dosis de IgG, con la finalidad de mantener las concentraciones séricas $\geq 800 \mathrm{mg} / \mathrm{dL}$. Es importante ajustar la dosis en pacientes con infecciones agudas o complicaciones autoinmunitarias (GRADE C1). ${ }^{11,20,22,24,25,68}$

R. Los eventos adversos provocados por la administración de IgG por vía intravenosa suelen relacionarse con la velocidad de infusión: por lo tanto, deben ajustarse y optimizar individualmente. Se recomienda reducir la velocidad de infusión y efectuar la adecuada reconstitución del producto cuando es liofilizado, con el propósito de disminuir la formación de agregados y reducir la posibilidad de eventos adversos. Los eventos adversos sistémicos son más frecuentes en pacientes que reciben IgG por vía intravenosa y los locales en sujetos que reciben IgG por vía subcutánea (GRADE D1). ${ }^{12,22,36,69-71}$

Inmunodeficiencias secundarias

Los principales tipos de inmunodeficiencia secundaria en que se encuentra justificada la indicación de lgG son: mieloma múltiple, leucemia linfocítica crónica, enfermedades con pérdida de proteínas, hipogammaglobulinemia secundaria a medicamentos (antiepilépticos, rituximab) e infección por $\mathrm{VIH}$ en pacientes pediátricos.

Mieloma múltiple

R. En pacientes con mieloma múltiple, hipogammaglobulinemia (concentración de IgG menor de $500 \mathrm{mg} / \mathrm{dL}$ ) e infecciones bacterianas recurrentes o graves, o deficiencia de respuesta de anticuerpos a polisacáridos comprobada, el tratamiento de reemplazo con IgG disminuye 
significativamente la tasa de infecciones graves (RR 0.45; IC95\% 0.27-0.75) e infecciones clínicamente documentadas (RR 0.49; IC95\% 0.39-0.61) sin mostrar efectos significativos en la supervivencia (RR 1.36; IC95\% 0.58-3.19) (GRADE A2). ${ }^{20,37,72-76}$

\section{Leucemia linfocítica crónica}

R. Los pacientes con leucemia linfocítica crónica con hipogammaglobulinemia (lgG $<500 \mathrm{mg}$ / dL) e infecciones bacterianas graves o recurrentes, aún con la prescripción profiláctica de antibióticos, se benefician del tratamiento de reemplazo con IgG y disminuye la tasa de infecciones graves (RR 0.45; IC95\% 0.27-0.75) (GRADE A1), sin efecto significativo en la supervivencia (GRADE A2)..$^{7,77,78}$

\section{Enfermedades con pérdida de proteínas}

Se ha documentado hipogammaglobulinemia e infecciones secundarias asociadas con diversas afecciones que incrementan la pérdida de proteínas en la zona intestinal (enteropatía con pérdida de proteínas, linfangiectasias), renal (síndrome nefrótico, nefritis asociada con enfermedades autoinmunitarias), torácica (quilotórax) y la piel (quemaduras). Sin embargo, no existen estudios controlados que evalúen la eficacia de la lgG por vía intravenosa o subcutánea en estos pacientes.

R. La evidencia es contradictoria con algunos reportes de casos clínicos o estudios abiertos no controlados que reportan disminución de la tasa de infecciones con la administración de IgG por vía intravenosa o subcutánea en dosis de reemplazo y otros que no documentan beneficios. No existe suficiente evidencia que respalde la indicación de IgG en estos pacientes, por lo que se sugiere individualizar cada caso (GRADE D2). ${ }^{79-94}$
Inmunodeficiencias secundarias provocadas por la prescripción de medicamentos

Se ha descrito hipogammaglobulinemia en individuos que reciben tratamiento con antiepilépticos (valproato, carbamazepina, fenitoína, lamotrigina, entre otros).

R. El tratamiento de reemplazo con IgG está indicado en pacientes con hipogammaglobulinemia (concentración de IgG menor de 500 mg/ dL) e infecciones graves o recurrentes asociadas con la prescripción de valproato, carbamazepina, fenitoína, lamotrigina, entre otros, cuando éstos no pueden sustituirse por otros fármacos o cuando la hipogammaglobulinemia persiste después de suspenderlos (GRADE D1). ${ }^{79,95-99}$

\section{Hipogammaglobulinemia secundaria al consumo} de rituximab

La prescripción cada vez más amplia de rituximab en el tratamiento de diversas afecciones neoplásicas y autoinmunitarias se relaciona con hipogammaglobulinemia grave o prolongada, especialmente cuando se indica con otros fármacos inmunosupresores.

R. El tratamiento de reemplazo con IgG está indicado en pacientes con hipogammaglobulinemia (concentración de IgG menor de 500 mg/ dL) e infecciones recurrentes (GRADE C1). ${ }^{99-106}$

\section{Infección pediátrica por virus de la inmunodeficiencia humana}

R. El tratamiento de reemplazo con IgG por vía intravenosa previene infecciones bacterianas graves en pacientes con VIH e hipogammaglobulinemia (IgG $<500 \mathrm{mg} / \mathrm{dL}$ ). Sin embargo, no ha demostrado disminución de la estancia hospitalaria ni de mortalidad en pacientes con infecciones bacterianas (GRADE A2). ${ }^{107,108}$ 
$R$. Debe prescribirse tratamiento de reemplazo con IgG en pacientes con VIH que cursen con infecciones bacterianas recurrentes graves sin hipogammaglobulinemia, pero con disfunción de anticuerpos comprobada mediante pruebas funcionales (GRADE 2C). ${ }^{109}$

R. En pacientes pediátricos con VIH y trombocitopenia relacionada con sangrado activo o cuenta plaquetaria menor de $10 \times 109 / L$ se recomienda la administración de IgG por vía intravenosa en dosis de $\mathbf{1} \mathrm{g} / \mathrm{kg}$ durante dos días (2 g/kg dosis total) (GRADE C1). ${ }^{110}$

\section{TRATAMIENTO DE INMUNOMODULACIÓN}

El efecto del tratamiento de inmunomodulación con altas dosis de $\lg \mathrm{G}$ es poco entendido y depende, en gran parte, de la integridad de la molécula de IgG y de las interacciones de la porción Fc con diversos inmunorreceptores y otros mecanismos que permanecen como hipótesis: ${ }^{111,112}$

- Unión con componentes del complemento activado solubilizan complejos inmunológicos e inhiben su fusión con blancos celulares.

- Bloqueo de receptores Fc e inhibición de las interacciones entre las células opsonizadas con autoanticuerpos y fagocitos.

- Coexistencia de anticuerpos antiidiotipo, antirreceptores $\alpha \beta$ de células T, anticomplejos principales de histocompatibilidad clase I, anti-CD45 (Fas) y otros autodeterminantes.

- Unión de anticuerpos antiidiotipo con sus blancos que generan dimerización de inmunoglobulinas e interacciones con receptores Fc.

- Incremento del catabolismo de autoanticuerpos por saturación del receptor FcRn.
- Regulación a la baja en la activación de linfocitos B e interacciones entre linfocitos T y B.

- Anticuerpos anticitocinas y con funciones antagonistas en receptores de citocinas.

- Inducción de receptores inhibitorios Fc $\gamma$ RIIb en macrófagos efectores (IgG sialilada).

- Expansión, activación de células T reguladoras, o ambas.

- Inhibición de la diferenciación y maduración de células dendríticas.

- Inhibición de la activación de células endoteliales y leucocitos.

La evidencia clínica de la prescripción de IgG como tratamiento inmunomodulador se ha incrementado gradualmente $y$, en términos generales, los beneficios se han estudiado, observado y aceptado para su aplicación por vía intravenosa. Sin embargo, cada vez se acumula evidencia en favor de altas dosis de lgG por vía subcutánea como alternativa de inmunomodulación, principalmente en pacientes con trastornos inmunitarios como: polineuropatía inflamatoria desmielinizante crónica, neuropatía motora multifocal, síndrome de Guillain-Barré, entre otras neuropatías autoinmunitarias desmielinizantes y miopatías inflamatorias. ${ }^{112}$

\section{ENFERMEDADES AUTOINMUNITARIAS}

Púrpura trombocitopénica inmunitaria

Han pasado más de 30 años desde que se informó el primer caso de prescripción de lgG en un paciente con púrpura trombocitopénica inmunitaria. Diferentes metanálisis concluyen que la IgG es tan efectiva como los corticosteroides, con una tasa de éxito de alrededor de $80 \%$ para aumentar la concentración de plaquetas a 50,000/ $\mathrm{mm}^{3}$ luego del quinto día de tratamiento. ${ }^{113}$ 
R. El tratamiento inmunomodulador de IgG por vía intravenosa está indicado como protocolo de primera o segunda línea en pacientes con púrpura trombocitopénica inmunitaria (GRADE A1). ${ }^{113,114}$

R. En pacientes con púrpura trombocitopénica inmunitaria recurrente la infusión repetida de IgG por vía intravenosa representa una alternativa a la esplenectomía (GRADE C2). ${ }^{115}$

R. En pacientes pediátricos con púrpura trombocitopénica inmunitaria el tratamiento inmunomodulador con IgG por vía intravenosa, en dosis de $0.8-1 \mathrm{~g} / \mathrm{kg}$, puede considerarse como protocolo de primera línea. Este tratamiento, comparado con la administración de ciclo corto de corticosteroides, incrementa rápidamente las cifras plaquetaria (GRADE B1). ${ }^{116,117}$

R. En adultos con púrpura trombocitopénica inmunitaria y con concentraciones menores de 30,000 plaquetas $/ \mathrm{mm}^{3}$ se recomienda iniciar el tratamiento inmunomodulador con IgG por vía intravenosa, en conjunto con corticosteroides sistémicos en ciclos largos. En pacientes con contraindicación para corticosteroides o efectos adversos graves puede indicarse IgG por vía intravenosa o anti-D como tratamiento de primera línea (GRADE B2). ${ }^{116,117}$

R. En pacientes con púrpura trombocitopénica inmunitaria el tratamiento inmunomodulador con IgG por vía intravenosa se administra en dosis única de $1 \mathrm{~g} / \mathrm{kg}$; en sujetos con resistencia al tratamiento o eventos recurrentes puede repetirse el mismo protocolo. La dosis de $0.8 \mathrm{~g} / \mathrm{kg}$ ha demostrado la misma eficacia en la mayoría de los casos; por lo tanto, disminuye los costos y posibles efectos adversos (GRADE B1). ${ }^{116,117}$

R. En pacientes con púrpura trombocitopénica inmunitaria crónica es efectiva la inmunomodulación con IgG por vía intravenosa, pues incrementa rápidamente la concentración pla- quetaria y pospone o evita la esplenectomía. La dosis recomendada es la misma que reciben los pacientes con púrpura trombocitopénica inmunitaria aguda (GRADE C2). ${ }^{116,117}$

R. Los efectos adversos relacionados con la administración de IgG por vía intravenosa en pacientes con púrpura trombocitopénica inmunitaria muestra una prevalencia de $5-75 \%$, generalmente leves. Los más comunes son: cefalea, dolor de espalda, escalofríos y fiebre. Algunos estudios han reportado anafilaxia, meningitis aséptica o hemólisis autoinmunitaria. No se ha reportado trasmisión de hepatitis $\mathbf{C} \mathbf{u}$ otro agente infeccioso en productos que utilizan pasos de inactivación de los virus durante su fabricación (GRADE C2). ${ }^{116,117}$

\section{Púrpura postransfusional}

R. La IgG por vía intravenosa puede ser un tratamiento eficaz en el tratamiento de la púrpura transfusional resistente a la prescripción de metilprednisolona (GRADE C2). ${ }^{117,118}$

\section{Neutropenia autoinmunitaria}

Las infecciones en pacientes con neutropenia autoinmunitaria suelen ser menores, habitualmente en el sistema respiratorio. Incluso $80 \%$ de los pacientes pediátricos se recupera espontáneamente. El tratamiento suele ser conservador, con filgrastim (G-CSF), en sujetos con infecciones graves o prescribirse antes de la cirugía.

R. En la población pediátrica con neutropenia autoinmunitaria se recomienda vigilancia expectante. En caso de requerir tratamiento, filgrastim (G-CSF) representa el protocolo de primera línea. En adultos suele haber una enfermedad subyacente (lupus, linfoproliferación), por lo que el tratamiento debe dirigirse a la enfermedad de base. ${ }^{118,119}$ 
R. No se recomienda prescribir de manera rutinaria la IgG por vía intravenosa en el tratamiento de la neutropenia autoinmunitaria. Se sugiere indicar IgG intravenosa cuando han fallado (dosis $1 \mathrm{~g} / \mathrm{kg} / \mathrm{en}$ un día) otro tipo de medicamentos (antibióticos y G-CSF) (GRADE D2). ${ }^{109,118-127}$

\section{Anemia hemolítica autoinmunitaria}

R. La evidencia de la prescripción de IgG por vía intravenosa en pacientes con anemia hemolítica autoinmunitaria es escasa. Los reportes disponibles no distinguen entre las distintas clases de anemia hemolítica autoinmunitaria (idiopática o secundaria, tibia o fría). La reacción del tratamiento es menor que la reportada con corticosteroides o esplenectomía; por tanto, la eficacia de la inmunomodulación con IgG por vía intravenosa es limitada y no se recomienda de manera rutinaria. Puede considerarse la prescripción de IgG por vía intravenosa, a dosis de $2 \mathrm{~g} / \mathrm{kg}$ en dos días, en conjunto con otros fármacos en casos graves de anemia hemolítica autoinmunitaria que amenacen la vida del paciente (GRADE D2). ${ }^{118,128}$

\section{Síndrome de Evans (anemia y trombocitopenia autoinmunitarias)}

R. La reacción de cualquier tratamiento en pacientes con síndrome de Evans (esteroide o danazol) es deficiente. En cuanto a la prescripción de IgG por vía intravenosa, la evidencia es escasa y la reacción es igualmente deficiente y transitoria, con recaídas frecuentes y tasa de respuesta mala. En estos casos, el tratamiento debe dirigirse a los síntomas primarios y descartar las causas subyacentes de las citopenias autoinmunitarias (dosis: $1 \mathrm{~g} / \mathrm{kg}$ en 1 día) (GRADE D2). ${ }^{118,125,126,128}$

\section{Dermatomiositis y polimiositis}

R. Por tratarse de enfermedades raras, no existe suficiente evidencia de calidad; sin embargo, los estudios disponibles han demostrado incremento de la fuerza muscular con la prescripción de IgG por vía intravenosa, sin provocar efectos adversos asociados con inmunosupresores, plasmaféresis y leucoféresis. Se considera un tratamiento efectivo y con buena tolerancia (GRADE B1); por tanto, puede recomendarse como tratamiento de primera línea. ${ }^{129,130}$

R. La IgG por vía intravenosa representa una buena opción en pacientes con polimiositisdermatomiositis resistente al tratamiento en exacerbación, rápidamente progresiva o grave y sujetos con alguna contraindicación para recibir corticosteroides u otro tipo de inmunodepresores (GRADE C1). La dosis sugerida es de $2 \mathrm{~g} / \mathrm{kg}$, con dosis total entre 2 y 5 días, cada mes por 3 a 6 meses. ${ }^{129,131,132}$

Miositis por cuerpos de inclusión (IBM)

R. No existe suficiente evidencia para emitir una recomendación. Se requieren estudios adicionales de largo plazo (GRADE C2). El esquema tradicional, al igual que en varias enfermedades autoinmunitarias, es de $2 \mathrm{~g} / \mathrm{kg}$ entre 2 y 5 días, cada mes por 3 a 6 meses (GRADE D2). ${ }^{133-135}$

Hemofilia adquirida

R. No existe suficiente evidencia para emitir una recomendación. Se requieren estudios adicionales. Cada caso debe individualizarse. Puede considerarse (dosis: 2 g/kg en dos días) como tratamiento adyuvante en casos graves o situaciones urgentes (GRADE C2). ${ }^{118,136,137}$

\section{Síndrome hemofagocítico asociado con virus}

R. De acuerdo con la evidencia disponible, no puede indicarse la IgG por vía intravenosa como tratamiento único en pacientes con linfohistiocistosis hemofagocítica familiar o relacionada con virus. Con base en un consenso de expertos, puede recomendarse como tratamiento coad- 
yuvante en casos graves o con rápido deterioro de la salud. El tratamiento con IgG por vía intravenosa (dosis: $2 \mathrm{~g} / \mathrm{kg}$ a lo largo de 2 días) no se considera inmunodepresor; por tanto, representa una opción segura y con función coadyuvante, particularmente en pacientes inmunodeficientes o graves. Se requieren más estudios controlados (GRADE 2D). ${ }^{118,138-145}$

\section{ENFERMEDADES INFLAMATORIAS}

Enfermedad de Kawasaki

La enfermedad de Kawasaki debe su nombre a la descripción de 50 pacientes pediátricos afectados con síndrome linfomucocutáneo febril agudo infantil por el doctor Tomisaku Kawasaki, y que se consideraba un proceso peculiar, que tiende a curarse de forma espontánea y con pronóstico favorable. ${ }^{146}$ Sin embargo, a principios del decenio de 1970 se reportaron 10 casos compatibles con enfermedad de Kawasaki que terminaron en muerte súbita; en las únicas 4 autopsias realizadas se identificaron aneurismas y trombosis en las arterias coronarias, por lo que tuvieron lugar nuevos acercamientos diagnósticos y terapéuticos. ${ }^{147}$ En 1984 el doctor Furusho realizó el primer ensayo clínico multicéntrico que demostró la eficacia y seguridad de la IgG por vía intravenosa, en dosis altas, para disminuir las anormalidades en las arterias coronarias de pacientes con enfermedad de Kawasaki; ${ }^{148}$ posteriormente, en 1991, los ambos estudios realizados por el grupo de Fred S. Rosen establecieron el esquema que hoy se considera el tratamiento de primera línea para esta enfermedad. ${ }^{149}$

R. La prescripción de IgG por vía intravenosa en conjunto con ácido acetilsalicílico en pacientes con enfermedad de Kawasaki disminuye de forma significativa la frecuencia de aneurismas coronarias. La dosis recomendada es de $\mathbf{2} \mathbf{~} / \mathbf{k g}$ (GRADE A1). ${ }^{148,150-153}$
R. Los pacientes que continúan con fiebre (enfermedad de Kawasaki resistente al tratamiento) después de la primera infusión de IgG tienen mayor riesgo de aneurismas y deben recibir una segunda dosis de (2 g/kg) (GRADE A1). ${ }^{150-155}$

\section{ALTERACIONES NEUROLÓGICAS}

Neuropatías periféricas desmielinizantes

\section{Síndrome de Guillain-Barré}

R. La IgG por vía intravenosa es efectiva en pacientes con síndrome de Guillain-Barré que con escala funcional de Hughes mayor a 3 requieren apoyo para caminar- en los primeros 15 días de iniciar los síntomas o hasta 4 semanas a partir del comienzo del padecimiento (GRADE A1). ${ }^{156-159}$

R. La población pediátrica con síndrome de GuiIlain-Barré debe recibir IgG intravenosa como tratamiento de primera línea (GRADE C1). ${ }^{156-159}$

R. Los efectos adversos de la IgG por vía intravenosa en pacientes con síndrome de Guillain-Barré son excepcionales, comparados con la plasmaféresis. Las reacciones adversas más frecuentes son escalofríos, náuseas, cefalea, mialgias, fatiga, fiebre, entre otros, pero ceden satisfactoriamente con el tratamiento sintomático. Son raros los reportes de efectos adversos graves (GRADE B1). ${ }^{159-162}$

R. La dosis recomendada de IgG intravenosa en pacientes con síndrome de Guillain-Barré es de $2 \mathrm{~g} / \mathrm{kg}$, como dosis total fraccionada, de 3 a 5 días (GRADE A2). ${ }^{159-162}$

R. Los pacientes con reacción inicial y que posteriormente recaen deben recibir, nuevamente, un segundo curso de IgG por vía intravenosa, sobre todo quienes sufren recidiva en las primeras ocho semanas (fluctuación relacionada con 
el tratamiento). Cuando las recidivas ocurren en más de tres ocasiones, en un período superior a ocho semanas, se establece el diagnóstico de polirradiculopatía desmielinizante inflamatoria crónica de inicio agudo (GRADE D2). ${ }^{159-162}$

R. No existe suficiente información para emitir la prescripción de IgG por vía intravenosa en pacientes con las variantes clínicas del síndrome de Guillain-Barré (síndrome de Miller Fisher y síndrome faringocervicobraquial). ${ }^{159-162}$

\section{Polirradiculoneuropatía desmielinizante inflamatoria crónica}

R. La IgG por vía intravenosa se considera el tratamiento de primera línea en pacientes con polirradiculoneuropatía desmielinizante inflamatoria crónica (PDIC), de moderada a grave. Es un tratamiento eficaz y seguro, mejora la calidad de vida y no provoca efectos adversos graves (GRADE A1). ${ }^{163-167}$

R. Los pacientes con síntomas leves de PDIC pueden mantenerse en vigilancia y sin tratamiento. Los pacientes con discapacidad moderada o grave pueden recibir tratamiento combinado con IgG intravenosa y corticosteroides antes de considerar la plasmaféresis (GRADE B2). ${ }^{163-167}$

R. Los pacientes con PDIC pueden recibir dosis de $1 \mathrm{~g} / \mathrm{kg}$ de $\mathrm{IgG}$ intravenosa cada tres semanas para sostener la mejoría. Aunque el beneficio puede considerarse breve, aumenta la calidad de vida. Se recomienda individualizar el tratamiento de cada paciente (0.4-1.2 g/kg cada 2-6 semanas). Cuando el paciente permanece estable con el régimen intermitente, se recomienda reducir la dosis. Aproximadamente $\mathbf{1 5} \%$ de los pacientes no reaccionan con ningún tratamiento (GRADE D2). ${ }^{165-167}$

R. En los últimos años se ha acumulado la evidencia en favor del tratamiento de inmuno- modulación con IgG por vía subcutánea a largo plazo en los pacientes con PDIC. Consideramos que se trata de un área de interés y con buenas expectativas; sin embargo, se requieren estudios adicionales para ofrecer una recomendación específica. (GRADE B2). ${ }^{112}$

Neuropatía multifocal motora con bloqueo de la conducción

R. La inmunomodulación con IgG por vía intravenosa representa la única opción eficaz en pacientes con neuropatía multifocal motora con bloqueo de la conducción (NMM); se ha demostrado que los corticosteroides y la plasmaféresis no producen resultados satisfactorios, incluso pueden empeorar el estado de salud. Los pacientes con NMM requieren terapia de mantenimiento a largo plazo, por lo que debe individualizarse cada caso, de acuerdo con la reacción al tratamiento (GRADE A1). ${ }^{167-170}$

R. La IgG intravenosa es el tratamiento de elección en pacientes con NMM moderada a grave, con dosis total de $2 \mathrm{~g} / \mathrm{kg}(0.4 \mathrm{~g} / \mathrm{kg} / \mathrm{d}$ por 5 días $)$ (GRADE A1). ${ }^{167-170}$

R. En pacientes con recurrencia, cuyo tratamiento inicial con IgG intravenosa fue efectivo, debe repetirse la misma dosis. La administración repetida debe establecerse con base en la reacción del tratamiento. El esquema de mantenimiento consiste en $1 \mathrm{~g} / \mathrm{kg}$ cada 2-4 semanas $02 \mathrm{~g} / \mathrm{kg}$ cada 1-2 meses. La mayoría de los pacientes requiere tratamiento repetido con IgG por vía intravenosa y aunque se mantienen estables por varios años, puede afectarse lentamente su salud por daño axonal progresivo, aún con la administración de dosis altas del tratamiento (GRADE D2). ${ }^{167-170}$

R. En los últimos años se ha incrementado la evidencia a favor del tratamiento de inmunomodulación con IgG por vía subcutánea a largo 
plazo en pacientes con NMM. Sin embargo, por tratarse de un área de interés y con buenas expectativas, deben realizarse más estudios para emitir una recomendación específica (GRADE B2). ${ }^{112}$

\section{Neuropatía periférica}

R. No existe suficiente evidencia para emitir una recomendación. Es importante considerar el tratamiento inmunomodulador con IgG intravenosa en pacientes con neuropatías periféricas paraneoplásicas sin reacción satisfactoria con otros medicamentos (dosis: 2 g/kg entre 2 y 5 días) (GRADE D2). ${ }^{144,160}$

\section{Neuropatía desmielinizante paraproteinémica} (gammapatía monoclonal)

R. El tratamiento inmunomodulador con IgG intravenosa representa el protocolo inicial en pacientes con discapacidad importante o con deterioro rápido. Se requieren estudios con mayor cantidad de pacientes, mejor diseñados y con seguimiento a largo plazo (de 6 a 12 meses como periodo mínimo) para obtener una mejor calidad de evidencia. La dosis recomendada es de $2 \mathrm{~g} / \mathrm{kg}$, dividida en 2 a 5 días consecutivos (GRADE C1). ${ }^{171-175}$

Otras enfermedades desmielinizantes (agudas y progresivas)

\section{Encefalomielitis aguda diseminada}

R. No existe suficiente evidencia para emitir una recomendación. La prescripción de IgG por vía intravenosa en pacientes con encefalomielitis aguda diseminada (EMDA) puede ser eficaz como tratamiento de segunda línea, cuando no los corticosteroides no ofrecen reacción satisfactoria. Hasta la fecha no existen estudios que comparen la efectividad entre IgG intravenosa, plasmaféresis y corticosteroides (GRADE 2D). ${ }^{176-180}$

\section{Neuromielitis óptica}

R. No existe suficiente evidencia para emitir una recomendación. La indicación de IgG por vía intravenosa, como tratamiento de segunda línea, ha demostrado disminución de las recidivas de pacientes con neuromielitis óptica (GRADE D2). ${ }^{181-182}$

Síndrome opsoclono-mioclono o encefalopatía mioclónica infantil

R. El tratamiento de inmunomodulación con IgG intravenosa ha demostrado eficacia en monoterapia o como coadyuvante en sujetos con síndrome opsoclono-mioclono o encefalopatía mioclónica infantil (SOM), independientemente de su etiología (GRADE D2). ${ }^{169-172,183-186}$

\section{Síndrome de persona rígida}

R. La IgG por vía intravenosa representa el tratamiento de primera línea en pacientes con síndrome de persona rígida, quienes reportan anticuerpos anti-GAD positivos. Se desconoce su efecto en pacientes con anticuerpos anti-

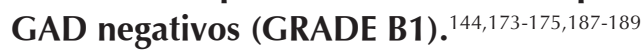

\section{Encefalitis límbica autoinmunitaria}

R. Los pacientes pediátricos y adultos con alto índice de sospecha de encefalitis límbica autoinmunitaria deben recibir tratamiento inmunomodulador con IgG intravenosa (en dosis de $400 \mathrm{mg} / \mathrm{kg} / \mathrm{d}$ por 5 días) y corticosteroides, plasmaféresis, o ambos. El $50 \%$ de los casos reacciona satisfactoriamente con la inmunoterapia de primera línea (IgG intravenosa, corticosteroides o plasmaféresis) y el $50 \%$ restante requiere tratamiento de segunda línea, 
con rituximab o la combinación de rituximab y ciclofosfamida. Entre 12 y $20 \%$ de los casos reporta recidivas; sin embargo, muestran buena reaccionan con inmunoterapia. Los pacientes sin reacción con la inmunoterapia de primera línea deben recibir terapias de segunda línea aisladas o en combinación (GRADE C2). ${ }^{176-178,190-192}$

Miastenia grave

R. La inmunomodulación con IgG por vía intravenosa, con dosis de $2 \mathrm{~g} / \mathrm{kg}$, representa el tratamiento de elección, eficaz a corto plazo, en sujetos con exacerbaciones agudas o casos graves de miastenia grave (MG) (GRADE A1). ${ }^{193-196}$

R. El tratamiento de inmunomodulación con IgG por vía intravenosa también es una buena opción en mujeres embarazadas con miastenia grave, debido a su eficacia y perfil de seguridad (GRADE A1). ${ }^{193-196}$

R. Los efectos adversos de la IgG intravenosa en pacientes con miastenia grave son raros, leves y de curación espontánea. Entre los principales se incluyen: fiebre, cefalea, transaminasemia y elevación de creatinina (GRADE B1). ${ }^{193-196}$

R. No existe suficiente evidencia para emitir una recomendación en cuanto a la inmunomodulación con IgG intravenosa como tratamiento de mantenimiento en pacientes con miastenia grave (GRADE D2). ${ }^{193-196}$

R. Está indicada la administración de IgG por vía intravenosa en pacientes con miastenia grave neonatal (GRADE D2). ${ }^{193-196}$

R. La dosis recomendada de IgG intravenosa en pacientes con exacerbación aguda de miastenia grave es de $\mathbf{2} \mathrm{g} / \mathrm{kg}$ en 2 días o, bien, $1 \mathrm{~g} /$ kg en aplicación única. No existe diferencia en cuanto a la aplicación de dosis mayores de $\mathbf{2}$ g/ kg (GRADE A2). ${ }^{193-196}$

\section{Síndrome miasténico Lambert-Eaton}

R. La inmunomodulación con IgG por vía intravenosa, en dosis de $2 \mathrm{~g} / \mathrm{kg}$ en 2 días consecutivos, ha demostrado efectos mínimos y transitorios (hasta 8 semanas) en pacientes con síndrome miasténico de Lambert-Eaton (LEMS) para reducir la debilidad (GRADE B2). ${ }^{144,162,183,184,197,198}$

\section{Epilepsia infantil intratable y síndromes} epilépticos

R. No existen suficientes estudios para emitir una recomendación de la prescripción rutinaria de IgG intravenosa en pacientes con epilepsia infantil intratable. La dosis de $2 \mathrm{~g} / \mathrm{kg}$ entre 2 y 5 días consecutivos ha reportado resultados variables (GRADE D2). ${ }^{185-192,199-206}$

\section{Esclerosis múltiple}

R. La indicación de $\operatorname{lgG}$ por vía intravenosa en pacientes con esclerosis múltiple se considerada un tratamiento de segunda línea en algunos países; sin embargo, en general no se encuentra indicada. No obstante, es el único inmunomodulador disponible durante el embarazo (GRADE C2). ${ }^{193-195,207-213}$

R. El tratamiento de pacientes con esclerosis múltiple por recidiva no ha demostrado efectos adicionales cuando se prescribe la combinación de IgG y corticosteroides. No se recomienda la administración de IgG intravenosa en monoterapia o en combinación con metilprednisolona en pacientes con algún brote/proceso/evento discapacitante (GRADE A1). ${ }^{193,195,214,215}$

R. Debe considerarse la prescripción de IgG por vía intravenosa en el tratamiento crónico de pacientes con esclerosis múltiple remitenterecurrente, en dosis de $2 \mathrm{~g} / \mathrm{kg}$ por 2 días, pues ha demostrado disminución de la discapacidad a un año y reducción de la tasa de recidivas a 3 años (GRADE C1). .07-213 $^{213}$ 


\section{ENFERMEDADES AUTOINMUNITARIAS EN PACIENTES PEDIÁTRICOS}

Prescripción de IgG intravenosa en reumatología pediátrica

\section{Artritis idiopática juvenil}

R. No está indicada la administración de IgG intravenosa en pacientes con artritis idiopática juvenil (GRADE C2).

En reportes de casos se ha señalado la aplicación de lgG intravenosa en pacientes con artritis idiopática juvenil, pero no se ha comprobado su eficacia en el control de la actividad de la enfermedad. ${ }^{216-220}$

R. De acuerdo con los reportes de casos clínicos, puede indicarse en pacientes con falla al tratamiento o con alergia a los fármacos modificadores de la enfermedad (FARMES), ya sean biológicos o no biológicos (GRADE C2). ${ }^{216-220}$

\section{Lupus eritematoso sistémico}

R. No se recomienda la prescripción de $\lg G$ intravenosa como tratamiento de primera línea en pacientes con lupus eritematoso sistémico (GRADE C2).

R. La prescripción del tratamiento debe establecerse en situaciones precisas (GRADE C2): 221-225

- En caso de falla al tratamiento de primera línea:

- alveolitis intersticial

- miocarditis lúpica

- trombocitopenia lúpica resistente al tratamiento

- vasculitis del sistema nervioso central

- mononeuritis
- neurolupus resistente al tratamiento (especialmente en sujetos con manifestaciones neuropsiquiátricas)

- nefropatía lúpica resistente al tratamiento

- En pacientes con: ${ }^{93,206-210}$

- lupus activo grave asociado con inmunodeficiencias (GRADE C2)

- lupus activo grave asociado con procesos infecciosos (GRADE C2)

- hipogammaglobulinemia asociada con rituximab (GRADE C2)

\section{Síndrome antifosfolípidos catastrófico}

R. La prescripción de $\lg G$ por vía intravenosa en pacientes pediátricos con síndrome antifosfolípido catastrófico representa una opción efectiva, al igual que la plasmaféresis. En algunos casos se ha descrito su indicación después de la plasmaféresis y en combinación con corticosteroides, anticoagulantes e inmunodepresores (GRADE C2). ${ }^{226,227}$

Vasculitis sistémicas y vasculitis asociadas con anticuerpos contra citoplasma de neutrófilos

R. La administración de $\operatorname{lgG}$ intravenosa en pacientes con vasculitis sistémicas y vasculitis asociadas con anticuerpos contra citoplasma de neutrófilos es un tratamiento que requiere evaluarse e individualizarse en cada paciente. No se recomienda su administración intravenosa ni subcutánea como tratamiento de primera línea (GRADE C2).

R. La IgG intravenosa puede indicarse únicamente en pacientes con vasculitis en los siguientes escenarios clínicos (GRADE C2):228,229

- Riesgo de muerte

- Resistencia al tratamiento convencional 
- Asociada con infecciones

- Nefritis

- Reducción de hormonas esteroides

- Intolerancia a fármacos inmunodepresores

Síndrome de activación de macrófagos

La prescripción de IgG intravenosa en pacientes con síndrome de activación de macrófagos, asociado con artritis idiopática juvenil sistémica, lupus eritematoso sistémico e infección en pacientes pediátricos con enfermedad reumática es una opción segura que puede indicarse en conjunto con corticosteroides, inmunodepresores e inmunomoduladores (etopósido, ciclosporina, etcétera).

R. Se recomienda la administración de IgG intravenosa en conjunto con inmunodepresores e inmunomoduladores (GRADE C2), principalmente en pacientes con: ${ }^{218-221,230-232}$

- Síndrome de activación de macrófagos asociado con artritis idiopática juvenil.

- Síndrome de activación de macrófagos asociado con lupus eritematoso sistémico.

\section{TRASPLANTES}

R. Los pacientes que recibirán trasplante de órgano sólido y quienes muestran sensibilización contra antígenos de histocompatibilidad (HLA) del donador pueden recibir IgG intravenosa, en dosis de $2 \mathrm{~g} / \mathrm{kg}$ por mes durante 4 meses antes del trasplante. La evidencia disponible proviene, principalmente, de trasplantes renales. Existe poca evidencia para emitir una recomendación del tratamiento en sujetos con trasplantes cardiacos, pulmonares o hepáticos (GRADE B1). ${ }^{233-238}$

R. Las diferentes presentaciones de IgG intravenosa disponibles se consideran seguras. En pacientes con insuficiencia renal y factores de riesgo para trombosis debe tenerse cautela $\mathrm{e}$ infundirse lentamente el tratamiento (GRADE B2). ${ }^{237}$

R. Se recomienda la administración de IgG por vía intravenosa ( $2 \mathrm{~g} / \mathrm{kg}$ total) luego de la plasmaféresis en receptores de trasplante de riñón, que cursen por un rechazo agudo mediado por anticuerpos, para prolongar la supervivencia del injerto (GRADE B2). ${ }^{237,238}$

R. Se sugiere vigilar las concentraciones séricas de IgG y administrar IgG por vía intravenosa en pacientes con enfermedad injerto contra huésped (EICH) crónica sistémica, moderada a grave, con hipogammaglobulinemia, con la finalidad de prevenir infecciones agregadas, $y$ en sujetos con EICH pulmonar para limitar la inflamación, que puede resultar en bronquiolitis obstructiva. La dosis recomendada es de $400 \mathrm{mg} / \mathrm{kg} / \mathrm{mensual}$, para mantener concentraciones séricas de IgG mayores de $500 \mathrm{mg} / \mathrm{dL}$ durante 10 meses después del trasplante (GRADE C1).227-229,239,240

Trasplante e infecciones

R. La prescripción de IgG intravenosa en combinación con ganciclovir, o foscarnet, está indicada en el tratamiento de la infección de novo por citomegalovirus de pacientes que recibieron trasplante de células progenitoras hematopoyéticas o de órgano sólido (GRADE B1). ${ }^{241,242}$

R. La IgG por vía intravenosa está contraindicada como profilaxis con infección por citomegalovirus, quienes recibieron trasplante de células progenitoras hematopoyéticas o de órgano sólido (GRADE B1). ${ }^{241,242}$

R. La IgG por vía intravenosa es el tratamiento de elección en pacientes postrasplantados con neumonitis causada por citomegalovirus, incluso ha demostrado mejor pronóstico y evolución 
cuando se prescribe en conjunto con ganciclovir (GRADE A1). ${ }^{241,242}$

R. La dosis de IgG intravenosa de $2 \mathrm{~g} / \mathrm{kg}$ ha demostrado eficacia para prevenir la pérdida de injerto en pacientes con trasplante renal asociada con nefropatía por virus BK (GRADE C2). ${ }^{241,242}$

R. La prescripción de IgG por vía intravenosa es eficaz en pacientes con enfermedad linfoproliferativa postrasplante por virus Epstein-Barr en conjunto con rituximab y ganciclovir (GRADE D2). $.23,244$

R. No se recomienda la administración rutinaria de IgG intravenosa para prevenir las infecciones postrasplante. La administración rutinaria no muestra disminución del riesgo de infección viral, bacteriana o micótica (GRADE A1). ${ }^{245-247}$

R. El tratamiento de reemplazo con IgG intravenosa $(400-600 \mathrm{mg} / \mathrm{kg} / \mathrm{mes})$ está indicado en pacientes con inmunodeficiencia primaria que recibirán trasplante de células progenitoras hematopoyéticas, en sujetos trasplantados con diagnóstico de mieloma múltiple, leucemia linfocítica crónica y en quienes padecen enfermedad injerto contra huésped con hipogammaglobulinemia, hasta que la concentración de IgG se encuentre en sus límites normales luego de 10 meses de recibir el trasplante (GRADE A1). ${ }^{248,249}$

R. En los pacientes sin hipogammaglobulinemia ( $\operatorname{lgG}<500 \mathrm{mg} / \mathrm{dL}$ ) no se ha demostrado que la administración mensual de IgG intravenosa sea capaz de reducir las complicaciones tardías luego del trasplante de células progenitoras hematopoyéticas (GRADE B2). ${ }^{233-238,250}$

\section{ENFERMEDADES RELACIONADAS CON INFECCIONES}

R. Existe evidencia que la IgG por vía intravenosa es capaz de reducir la tasa de mortalidad en niños y adultos con sepsis y choque séptico.
La dosis recomendada es de 1-2 g/kg (GRADE 1A). ${ }^{251,252}$

R. La IgG por vía intravenosa incrementa la supervivencia de pacientes con síndrome de choque tóxico (dosis de 0.5 a $1 \mathrm{~g} / \mathrm{kg} / \mathrm{d}$ por 1-6 días), a partir del diagnóstico de la enfermedad (GRADE 2 C2). ${ }^{253-255}$

R. Los pacientes con colitis grave o multirrecurrente por Clostridium difficile pueden recibir IgG por vía intravenosa, en dosis de $400 \mathrm{mg} / \mathrm{kg}$ durante 1 a 4 días, pues ha demostrado disminución de la morbilidad y mortalidad una semana después de iniciar el tratamiento convencional (GRADE C2). ${ }^{255-259}$

R. Está indicado el tratamiento de IgG por vía intravenosa en pacientes con anemia de serie roja por parvovirus B19 (GRADE C2). ${ }^{260}$

Sepsis neonatal

R. No existe evidencia que respalde la eficacia de la IgG intravenosa de forma rutinaria para disminuir la mortalidad de pacientes con sepsis neonatal. ${ }^{261,262}$

No existe evidencia que respalde la prescripción profiláctica (sepsis) rutinaria de IgG intravenosa en recién nacidos prematuros o con bajo peso (GRADE A1). ${ }^{251-253,263}$

\section{USOS MISCELÁNEOS}

\section{Trombocitopenia aloinmunitaria neonatal}

R. La dosis de IgG intravenosa de $2 \mathrm{~g} / \mathrm{kg}$ en 2 días puede ser eficaz en neonatos con trombocitopenia aloinmunitaria para evitar la destrucción de plaquetas trasfundidas. ${ }^{264,265}$

R. En pacientes con embarazos subsecuentes puede administrase la IgG por vía intravenosa, 
en dosis de 0.5-1 g/ $\mathrm{kg} /$ semanal en combinación con corticosteroides, luego de comprobar el fenómeno-proceso autoinmunitario, para prevenir la trombocitopenia en el recién nacido (GRADE C2). ${ }^{266-271}$

\section{Enfermedad hemolítica neonatal}

R. La IgG por vía intravenosa, en dosis de $\mathbf{5 0 0}$ $\mathrm{mg} / \mathrm{kg}$, puede reducir el requerimiento de exsanguinotransfusión en neonatos con enfermedad hemolítica neonatal. Se ha observado que el tratamiento con IgG intravenosa durante el embarazo, en monoterapia o combinada con corticosteroides, es eficaz para prevenir la enfermedad hemolítica del recién nacido (GRADE C2). 232,238,254-256,272-274

\section{Enfermedades dermatológicas}

R. La IgG por vía intravenosa, en dosis $\geq 2 \mathrm{~g} / \mathrm{kg}$, está indicada en pacientes con necrólisis epidérmica tóxica y síndrome de Stevens-Johnson (GRADE B2). ${ }^{275-277}$

R. La administración de IgG por vía intravenosa puede indicarse como tratamiento coadyuvante en pacientes con pénfigo buloso grave, quienes requieren control rápido, con falla al tratamiento o en quienes tienen contraindicación para otro tipo de fármacos. La dosis recomendada es de $2 \mathrm{~g} / \mathrm{kg}$ (GRADE C2). ${ }^{278-279}$

R. La administración de IgG por vía intravenosa en dosis altas (1-2 g/kg) es eficaz en pacientes con psoriasis resistente y grave, $y$ en quienes padecen artritis psoriásica (GRADE C2). ${ }^{279-282}$

R. No está indicado el tratamiento rutinario de IgG por vía intravenosa en pacientes con dermatitis atópica. Puede administrarse para el control, a corto plazo, de formas graves y resistentes a otros tratamientos (GRADE D2). ${ }^{283-286}$
R. No está indicado el tratamiento rutinario de IgG por vía intravenosa en pacientes con urticaria; sólo puede prescribirse como último recurso en casos graves de urticaria autoinmunitaria (GRADE D2). ${ }^{282}$

\section{Enfermedades neurocognitivas}

R. No se recomienda la administración de $\lg G$ por vía intravenosa en pacientes con autismo (GRADE B1). ${ }^{287-291}$

R: Está indicada la prescripción de IgG intravenosa, en dosis de $2 \mathrm{~g} / \mathrm{kg}$, en pacientes pediátricos con formas graves y resistentes al tratamiento con antibióticos por trastornos neuropsiquiátricos autoinmunitarios asociados con infecciones por estreptococos (PANDAS) (GRADE C2). ${ }^{291,292}$

R. La IgG por vía intravenosa está contraindicada en el tratamiento del síndrome de fatiga crónica (GRADE A1). ${ }^{293-296}$

Fibrosis quística

R. La IgG por vía intravenosa es un tratamiento eficaz en pacientes con fibrosis quística asociada con hipogammaglobulinemia (GRADE C2). ${ }^{297}$

Miocarditis viral aguda

R. No existe suficiente evidencia para recomendar la administración rutinaria de $\operatorname{lgG}$ intravenosa en pacientes con miocarditis viral aguda (GRADE D2). ${ }^{298-299}$

\section{Aborto involuntario recurrente}

R. La administración de IgG por vía intravenosa en el tratamiento del aborto involuntario recurrente no se justifica fuera del contexto de ensayos controlados aleatorizados bien diseñados. Hasta la fecha se desconoce algún mecanismo de acción comprobado, incluso no 


\section{existen algoritmos diagnósticos para identificar a los pacientes capaces de beneficiarse con dicho tratamiento (GRADE A1). ${ }^{300,301}$}

\section{REFERENCIAS}

1. Kivity S, Katz U, Daniel N, Nussinovitch U, Papageorgiou N, Shoenfeld $Y$, Kivity $S$. Evidence for the use of intravenous immunoglobulins a review of the literature. Clin Rev Allergy Immunol 2010;38(2-3):201-69.

2. Bruton O. Agammaglobulinemia. Pediatrics 1952;9(6):722728.

3. Barandun S, Baumgartner C, Hirt A, Hofer F, Wagner HP, Imbach P. High-dose intravenous gamma globulin therapy of refractory in particular idiopathic thrombocytopenia in childhood. Helv Peiat Acta 1981;36(1):81-86.

4. Geha RS, Charles A, Janeway, Fred S. Rosen. The discovery of gamma globulin therapy and primary immunodeficiency diseases at Boston Children's Hospital. J Allergy Clin Immunol 2005;116(4):937-940.

5. Consejo de Salubridad General (2016). Cuadro básico y catálogo de medicamentos. [en línea]. Dirección URL: <http:// www.csg.gob.mx/descargas/pdfs/cuadro_basico/CB2014/ index/EDICION_2016_MEDICAMENTOS.pdf>.

6. U.S. Food \& Drug Administration. (2017, May) Immune Globulin Intravenous (IGIV) Indications. [en línea]. Dirección URL: <https://www.fda.gov/BiologicsBloodVaccines/BloodBloodProducts/ApprovedProducts/LicensedProductsBLAs/FractionatedPlasmaProducts/ucm133691.htm>.

7. Wilson MC, Nishikawa J, Haywards RS, Richardson WS. The well-built clinical question: a key to evidence-based decisions. ACP J Club 1995;123(3):A12-3.

8. Oxman AD, Vist GE, Kunz R, Falck-Ytter Y, Alonso-Coello $P$, Schünemann HJ, Gordon H. GRADE: an emerging consensus on rating quality of evidence and strength of recommendations. BMJ 2008;336:924.

9. Ochoa-Carrillo FJ, Oñate-Ocaña LF. Sistema GRADE para clasificar nivel de evidencia y grado de las recomendaciones para la elaboración de guías de buena práctica clínica. Cir Ciruj 2009;77:417-419.

10. U.S. Food \& Drug Administration. (2008, June) Guidance for Industry: Safety, Efficacy, and Pharmacokinetic Studies to Support Marketing of Immune Globulin Intravenous (Human) as Replacement Therapy for Primary Humoral Immunodeficiency. [en línea]. Dirección URL: <https://www. fda.gov/biologicsbloodvaccines/guidancecomplianceregulatoryinformation/guidances/blood/ucm072130.htm>.

11. Khan DA, Ballas ZK, Chinen J, Frank MM, Hsu JT, Bonilla FA. Practice parameter for the diagnosis and management of primary immunodeficiency. J Allergy Clin Immunol 2015;136(5):1186-1205.

12. Spickett GP, Ericson D, Engl W, Eibl MM, Bjorkander J, Chapel HM. The comparison of the efficacy and safety of intravenous versus subcutaneous immunoglobulin replacement therapy. J Clin Immunol 2000;20(2):94-100.
13. Berger M. Subcutaneous immunoglobulin replacement in primary immunodeficiencies. Clin Immunol 2004;112(1):1-7.

14. Belohradsky BH, Berger M, Borte M, Hagan J, Jolles S, Orange JS. Evaluation of correlation between dose and clinical outcomes in subcutaneous immunoglobulin replacement therapy. Clin Exp Immunol 2012;169(2):172-181.

15. Shapiro R. Subcutaneous immunoglobulin (16 or $20 \%$ ) therapy in obese patients with primary immunodeficiency: a retrospective analysis of administration by infusion pump or subcutaneous rapid push. Clin Exp Immunol 2013;173(2):365-371.

16. Fasth A, Lingman-Frame J. Subcutaneous immunoglobulin for primary and secondary immunodeficiencies: an evidence-based review. Drugs 2013;73(12):1307-1319.

17. Chapel H, Chevret S, Lucas M, Malphettes M, Fieschi C, Gouilleux-Gruart V. Efficiency of immunoglobulin G replacement therapy in common variable immunodeficiency: correlations with clinical phenotype and polymorphism of the neonatal Fc receptor. Clin Exp Immunol 2013;171(2):186-194.

18. Flato UP, Ferri CP, Fernandes JG, Buehler AM. Is there evidence for recommending specific intravenous immunoglobulin formulations? A systematic review of headto-head randomized controlled trials. Eur J Pharmacol 2015;747:96-104.

19. Lacobini M, Leonardi L, Smacchia P, Antonetti L, Giancane G, Duse M. Transient hypogammaglobulinemia of infancy: intravenous immunoglobulin as first line therapy. Int J Immunopathol Pharmacol 2010;23:349-353.

20. National Blood Authority. (2012, August) Criteria for the clinical use of intravenous immuno-globulin in Australia Second Edition (IVIG Criteria Second Edition). [en línea]. Dirección URL: <https://www.blood.gov.au/ivig-criteria" https://www.blood.gov.au/ivig-criteria>.

21. Dimitriades VR, Sorensen RU, Wall LA. Specific Antibody Deficiencies. Immunol Allergy Clin North Am 2015;35(4):659-670.

22. Costa Carvalho BT, Grumach AS, King A, Bezrodnik L, Oleastro $\mathrm{M}$, Condino-Neto A. Guidelines for the use of human immunoglobulin therapy in patients with primary immunodeficiencies in Latin America. Allergol Immunopathol (Madr) 2014;42(3):245-260.

23. Cunningham-Rundles $C$. How I treat common variable immune deficiency. Blood 2010;116:7-15.

24. Lee M, Lortan J, Lopez-Granados E, Misbah S, Chapel H, Lucas M. Infection outcomes in patients with common variable immunodeficiency disorders: relationship to immunoglobulin therapy over 22 years. J Allergy Clin Immunol 2010;125:1354-1360.

25. Grossman WJ, Navickis RJ, Wilkes MM, Orange JS. Impact of through IgG on pneumonia incidence in primary immunodeficiency: A meta-analysis of clinical studies. Clin Immunol 2010;137(1):21-30.

26. Picard C, Gaspar B, Al-Herz W, Bousfiha A, Casanova JL, et.al International Union of Immunological Societies: 2017 Primary Immunodeficiency Diseases Committee 
Report on Inborn Errors of Immunity" J Clin Immunol 2018;38(1):96-128

27. Buckley RH, Boyle JM. Population prevalence of diagnosed primary immunodeficiency diseases in the United States. J Clin Immunol 2007;27(5):497-502.

28. Orange JS, Bonilla F, Chinen J, Chinn IK, Dorsey M, Perez $E E$. Update on the use of immunoglobulin in human disease: A review of evidence. J Allergy Clin Immunol 2017;139(3S):S1-S46.

29. Nacinovich R, Bomba M, Cassani M, Molinaro A, Sciotto A, Soresina A. The quality of life of children and adolescents with X-linked agammaglobulinemia. J Clin Immunol 2009;29:501-7.

30. Marino MC, Lederman HM, Jones SM, Sullivan K, Burks AW, Winkelstein JA. X-linked agammaglobulinemia: report on a United States Registry of 201 patients. Medicine (Baltimore) 2006;85:193-202.

31. Conley ME, James C, Howard V, Boyle J, Winkelstein JA. Adults with X-linked agammaglobulinemia: impact of disease on daily lives, quality of life, educational and socioeconomic status, knowledge of inheritance, and reproductive attitudes. Medicine (Baltimore) 2008;87:253-8.

32. Debré M, De Blic J, de Sauverzac R, Sayegh N, Jabado N, Quartier P. Earyl and prolonged intravenous immunoglobulin replacement therapy in childhood agammaglobulinemia: a retrospective survey of 31 patients. J Pediatr 1999;134(5):589-596.

33. Hoepelman IM, ellerbroek PM, Maarschalk-Ellerbroek LJ. Immunoglobulin treatment in primary antibody deficiency. Int J Antimicrob Agents 2011;37:396-404.

34. Boyle J, Ballow M, Boyle M, Berger M, Bleesing J, Yong PL. Use of intra-venous immunoglobulin and adjunctive therapies in the treatment of primary immunodeficiencies: a working group report of and study by the Primary Immunodeficiency Committee of the American Academy of Allergy Asthma and Immunology. Clin Immunol 2010;135:255-263.

35. Berger $M$. Principles of and advances in immunoglobulin replacement therapy for primary immunodeficiency. Immunol Allergy Clin North Am 2008;28(2):413-437.

36. Palda V, Bowen T, Haddad E, Issekutz TB, Mazer B, Shehata $N$. The use of immunoglobulin therapy for patients with primary immune deficiency: an evidence-based practice guideline. Transfus Med Rev 2010;24(1):S28-50.

37. Department of Health. (2011, August) Guidance Clinical guidelines for immunoglobulin use (second edition update). [en línea]. Dirección URL: <https://www.gov.uk/ government/publications/clinical-guidelines-for-immunoglobulin-use-second-edition-update>

38. Hossny EM, Weiler CR, Ballow M, Berger M, Bonilla FA, Orange JS. Use of intravenous immunoglobulin in human disease: a review of evidence by members of the Primary Immunodeficiency Committee of the American Academy of Allergy, Asthma and Immunology. J Allergy Clin Immunol 2006;117(Suppl 4):S525-53.

39. Zhang L, Li Y, Quan S, Liang Y, Zeng L, Song J. $20 \%$ subcutaneous immunoglobulin for patients with primary immunodeficiency diseases: A systematic review. Int Immunopharmacol 2015;25(2):457-464.

40. Sanford M. “Human immunoglobulin $10 \%$ with recombinant human hyaluronidase: replacement therapy in patients with primary immunodeficiency disorders". BioDrugs 2014;28(4):411-420.

41. Jain N, Pierce LR. Risks associated with the use of intravenous immunoglobulin. Transf Med Rev 2003;17:241-251.

42. Barlan I, Chapel H, Costa-Carvalho BT, Cunningham-Rundels C, dela Morena MT, Bonilla FA. ICON: international consensus document for common variable immunodeficiency (CVID). J Allergy Clin Immunol Pract 2016;36(3):173-178.

43. Bodian C, Cunningham-Rundles C. Common variable immunodeficiency: clinical and immunological features fo 248 patients. Clin Immunol 1999;92(1):34-48.

44. Razvi S, Cunningham-Rundles C, Busse PJ. Efficacy of intravenous immunoglobulin in the prevention of pneumonia in patients with common variable immunodeficiency. J Allergy Clin Immunol 2002;109:1001-4.

45. Lucas $M$, Patel $S$, Lee $M$, Cunningham-Rundles $C$, Resnick E, Chapel H. Confirmation and improvement of criteria for clinical phenotyping in common variable immunodeficiency disorders in replicate cohorts. J allergy Clin Immunol 2012;130:1197-1198.

46. Cunningham-Rundles $C$. The many faces of common variable immunodeficiency. Hematology Am Soc Hematol Educ Program 2012;2012:301-305.

47. Cerediht MN, Oksenhendler GL, Warnatz K, Gathman B. Clinical picture and treatment of 2212 patients with common variable immunodeficiency. J Allergy Clin Immunol 2014;134:116-126.

48. Vuorinen T, Rantakokko-Jalava K, Osterback R, Ruuskanen $\mathrm{O}$, Kainulainen L. Recurrent and persistent respiratory tract viral infections in patients with primary hupogammaglobulinemia. J Allergy Clin Immunol 2010;126:120-6.

49. Azaris E, Edeer Karacca, Memmedova L. Does intravenous immunoglobulin therapy prolong immunodeficiency in transient hypogammaglobulinemia of infancy? Pediatr Resp 2013;5(3)e14.

50. Ballow M, Stiehm ER, Ballas ZK, Chinen J, De la Morena M, Orange JS. Use and interpretation of diagnostic vaccination in primary immunodeficiency: a working group report of the Basic and Clinical Immunology Interest Section of the American Academy of Allergy, Asthma and Immunology. J Allergy Clin Immunol 2012;130(Suppl 3):S1-S24.

51. Bonagura VR. Using intravenous immunoglobulin (IVIG) to treat patients with primary immune deficiency disease. $J$ Clin Immunol 2013;33(Suppl 2):S90-4.

52. Ellerbroek PM, Maarschalk-Ellerbroek LJ Hoepelman IM. Immunoglobulin treatment in primary antibody deficiency. Int J Antimicrob Agents 2011;37:396-404.

53. Koskinen S, Laippala P, Laine S, Miettinen A, Aittoniemi J. The significance of IgG subclasses and mannan-binding lectin (MBL) for susceptibility to infection in apparently healthy adults with IgA deficiency". Clin Exp Immunol 1999;116:505-508. 
Espinosa-Rosales FJ et al. Inmunoglobulina G para reemplazo e inmunomodulación

54. Hammarstrom L, Wang N. IgA deficiency: what is new?. Curr Opin Allergy Clin Immunol 2012;12:602-8.

55. Buckley RH. B-cell function in severe combined immunodeficiency after stem cell or gene therapy: a review. J Allergy Clin Immunol 2010;125:790-7.

56. Roberts RL, Moore TB, Stiehm ER, Chan WY. Cord blood transplants for SCID: better b-cell engraftment?. J Pediatr Hematol Oncol 2013;35(1):e14-8.

57. Jing H, Ozgur T, Ayvaz D, Strauss-Albee DM, Ersoy-Evans $\mathrm{S}$, Sanal O. Additional diverse findings expand the clinical presentation of DICK8 deficiency. J Clin Immunol 2012;32:698-708.

58. Davis JC, Lamborn IT, Freeman AF, Jing H, Favreau AJ, Zhang Q. Combined immunodeficiency associated with DOCK8 mutations. N Eng J Med 2009;361:2046-2055.

59. Melki I, Natividad A, Puel An, Fieschi C, Yun L, Chandesris MO. Autosomal dominant STAT3 deficiency and hyper-IgE syndrome: molecular, cellular and clinical features from a French national survey. Medicine (Baltimore) 2012;91:e1e19.

60. Holand SM, Freeman AF, Sowerwine KH. Hyper-IgE syndrome update. Ann N Y Acad Sci 2012;1250:25-32.

61. Notarangelo LD, Ochs HD, Albert MH. Clinical spectrum, pathophysiology and treatment of the Wiskott-Aldrich syndrome. Curr Opin Hematol 2011;18:42-8.

62. Bittner TC, Nonyama S, Notarangelo LD, Burns S, Imai K, Albert MH. X-linked thrombocytopenia (XLT) due to WAS mutations: clinical characteristics, long-term outcome and treatment options. Blood 2010;115:3231-8.

63. Gilmour KC, Veys P, Gennery AR, Slatter MA, Chapel H, Booth C. X-linked lymphoproliferative disease due to SAP/ SH2D1A deficiency: a multicenter study on the manifestations, managmenet and outcome of the disease. Blood 2011;117:53-62.

64. Madden L, Kitchen BJ, Mody R, McCimon B, Jordan MB, Marsch RA. XIAP deficiency: a unnique primary immunodeficiency best classified as X-linked familial hemophagocytic lymphohistiocytosis and not as X-linked lymphoproliferative disease. Blood 2010;116:1079-1082.

65. Keenan JE, Kinney MC, Leo H, Jain N, Ma CA, LópezGranados E. A novel mutation in NFKBIA/IKBA results in a degradation-resistant $\mathrm{N}$-truncated protein and is associated with ecodermal dysplasia with immunodeficiency. Hum Mutat 2008;29(6):861-868.

66. Monaco Shawver L, Solt LA, Madge LA, Banerjee PP, May MJ, Hanson EP. Hypomorphic nuclear factor kappa-B essential modulation mutation database and reconstitution system identifies phenotypic and immunologic diversity. J Allergy Clin Immunol 2008;122:1169-77.

67. Malech HL, Kawai T. WHIM syndrome: congenital immune deficiency disease. Curr Opin Hematol 2009;16:20-6.

68. Ersoy F, Sarial O, Kilic S, Metin A, Tezcan I, Bayrakci B. The efficacy of immunoglobulin replacement therapy in the long-term follow-up of the B-cell deficiencies (XLA, HIM, CVID). Turk J Pediatr 2005;47:239-246.
69. Barbieri C, Cantani A, Solano A, Longhi MA, Businco L, Galli $E$. Treatment with gammaglobulin preparation for intravenous use in children with humoral immunodeficiency: clinical and immunologic follor-up. Ann Allergy 1990;64(2 Pt 1):147-150.

70. Siegal FP, Smithwick EM, Lion-Boulé A, CunninghamRundles S, O'Malley J, Cunningham-Rundles C. Efficacy of intravenous immunoglobulin in primary humoral immunodeficiency disease. Ann Intern Med 1984;101(4):435-9.

71. Lee M, Hargreaves R, Paphilon DH, Prentice AG, Chapel HM. Randomised trial of intravenous immunoglobulin as prohyplaxis against infection in plateau-phase multiple myeloma. The UK Group for Immunoglobulin Replacement Therapy in Multiple Myeloma. Lancet 1994;343:1059-1063.

72. Brugiatelli $\mathrm{M}$, Carotenuto $\mathrm{M}$, Musto $\mathrm{P}$. Prophylaxis against infections with intravenous immunoglobulins in multiple myeloma. Br J Haematol 1995;89(4):945-6.

73. Gafter-Gvili A, Paul M, Ben-Bassat I, Leibovici L, Shpilberg O, Raanani P. Immunoglobulin prophylaxis in chronic lymphocytic leukemia and multiple myeloma: systematic review and meta-analysis. Leul Lymphoma 2009;50:764-772.

74. Ahmedzai SH, Ashcroft J, D'Sa S, Littlewood T, Low E, Snowden JA. Guidelines for supportive care in multiple myeloma. Br J Haematol 2011;154(1):76-103.

75. Guillevin L. Pharmacoeconomics of immunoglobulins and indications for their use. Curr Opin Allergy Clin Immunol 2013;13(Suppl 2):S53-5.

76. British Committee for Standars in Haematology. Guidelines on the diagnosis, investigation and management of chronic lymphocytic leukaemia. Br J Haematol 2012;159(5):541-64.

77. Cooperative Group for the Study of Immunoglobulin in Chronic Lymphocytic Leukemia. Intravenous immunoglobulin for the prevention of infection in chronic lymphocityc leukemia. A randomized controlled clinical trial. N Eng J Med 1988;319:902-907.

78. Misbah SA, Dhalla F. Secondary antibody deficiencies". Curr Opin allergy Clin Immunol 2015;15(6):505-513.

79. Buckland MS, Grigoriadou S, Longhurst HJ, Duraisingham SS. Secondary antibody deficiency. Expert Rev Clin Immunol 2014;10(5):583-591.

80. Dolman KM, Tabbers MM, Braamskamp MJ. Clinical practice. Protein-losing enteropathy in children. Eur J Pediatr 2010;169:1179-1185.

81. Lang DM, Rose ME. Evaluating and managing hypogammaglobulinemia. Cleve Clin J Med 2006;73(2):133-137.

82. Bellanger J, Vignes S. Primary intestinal lymphangiectasia (Waldmann's disease). Orphanet J Rare Dis 2008;3:5.

83. Boelens JJ, Versteegh FG, Weemaes C, Wulffraat NM, Dierselhuis MP. Recurrent and opportunistic infections in children with primary intestinal lymphangiectasia. J Pediatr Gastroenterol Nutr 2007;44:382-385.

84. Alfonsi L, Cella A, Pasanisi F, Contaldo F, Alfano VTG. Stable reversal of pathologic signs of primitive intestinal lymphan- 
giectasia with a hypolipidic, MCT-enriched diet. Nutrition 2000;16:303-304.

85. Scotta MS, Ugazio AG, De Giacomo CMG. Administration of intravenous immunoglobulin in two children with hypogammaglobulinemia due to protein losing enteropathy. Clin Exp Immunol 1985;60:447-448.

86. Yokoyama $\mathrm{H}$, Tomosugi $\mathrm{H}$, Hisada $\mathrm{Y}$, Ohta S, Takaeda M, Ogi MYH. Risk factors for infection and immunoglobulin replacement therapy in adult nephrotic syndrome. Am J Kidney Dis 1994;24(3):427-436.

87. Yi Z, Wang X, Wu X, Zhang X, He Q, Dang X. Preventive efficiency of IVIG on nosocomial infection in the children with nephrotic syndrome. Hunan Yi Ke Da Xue Xue Bao 1999;24(3):290-2.

88. Petko M, Hayward MP, Nair SK. Aetiology and management of chylothorax in adults. Eur J Cardiothorac Surg 2007;32:362-369.

89. Blades Z, Anderson PB, McGrath EE. Chylothorax: aetiology, diagnosis and therapeutic options. Respir Med 2010;104:1-8.

90. Geha RS, Bonilla FA, Orange JS. Acute chylothorax in children: selective retention of memory $T$ cells and natural killer cells. J Pediatr 2003;93:220-224

91. Hansmann $M$, Bartmann $P$, Heep A, Wasmuth-Pietzuch A. Congenital chylothorax: lymphopenia and high risk of neonatal infections. Acta Paediatr 2004;93:220-224.

92. Ramaiah RN, Cale CM, Hartley JC, Brown KL, Hoskote AU. Role of immunoglobulin supplementation for secondary immunodeficiency associated with chylothorax after pediatric cardiothoracic surgery. Pedatr Crit Care Med 2012;13(5):535-541.

93. Davis C, Rieman MT, Kopcha R, Phan H, Greenhalgh D, Lyons JM. Prophylactic intravenous immune globulin and polymixin $B$ decrease the incidence of septic episodes and hospital length of stay in severley burned children. J Burn Care Res 2006;27(6):813-8.

94. Moran KT, Thupari J, Allo M, Winchurch RA, Munster AM. Prophylactic intravenous immunoglobulin replacement in high-risk burn patients. J Burn Care Rehabil 1987;8(5):376-80.

95. Lee Hs, Jang PS, Kim YH, Eom TH. Valproate-induced panhypogammaglobulinemia. Neurol Sci 2012;34(6):1003-4.

96. Goksugur N, Eroglu S, Tabak O, Canbakan B, Ozaras R, Ozaras N. Carbamazepine-induced hypogam Imaglobulinemia. Seizure 2012;21(3):229-231.

97. Hosseini SA, Abolmaali S, Biglari M, Azizi R, Farghadan $M$, Ashrafi M. Effect of antiepileptic drugs on serum immunoglobulin levels in children. Acta Neurol Belg 2010;110(1):65-70.

98. Bansal A, Hayman G. Antibody deficiency associated with carbamazepine. BMJ 2002;325:1213.

99. Price C, Barmettler S. Continuing IgG replacement therapy for hypogammaglobulinemia after rituximab-for how long? J Allergy Clin Immunol 2015;136(5):1407-9.
100. Jones RB, Smith RM, Alberici F, Kumaratne DS, Burns S, Roberts DM. Immunoglobulin $G$ replacement for the treatment of infective complications of rituximab-associated hypogammaglobulinemia in autoimmune disease: a case series. J Autoimmun 2015;57:24-9.

101. Malipiero G, Cinetto F, Agostini C, Compagno N. Immunoglobulin replacement therapy in secondary hypogammaglobulinemia. Front Immunol 2014;5:626.

102. Jones RB, Smith RM, Alberici F, Kumaratne DS, Burns S, Roberts DM. Rituximab-associated hypogammaglobulinemia: incidence, predictors and outcomes in patients with multisystem autoimmune disease. J Autoimmun 2015;57:60-65.

103. Kopoyltsova Y, Khokhar A, Lam F, Bonagura V, Kaplan B. Rituximab and immune deficiency: case series and review of the literature. J Allergy Clin Immunol Pract 2014;2(5):594-600.

104. Kiani-Alikhan S, Manson AL, Verma N, Leandro M, Gurugama NP, Makatsori M. Hypogammaglobulinaemia after rituximab treatment-incidence and outcomes. QJM 2014;107(10):821-8.

105. Cinetto F, Semenzato G, Agostini C, Compagno N. Subcutaneous immunoglobulin in lymphoproliferative disorders and rituximab-related secondary hypogammaglobulinemia: a single-center experience in 61 patients. Haematologica 2014;99(6):1101-6.

106. Bader L, Nossent H, Besada E. Sustained hypogammaglobulinemia under rituximab maintenance therapy could increase in the risk for serious infections: a report of two cases. Rheumatol Int 2013;33(6):1643-1644.

107. Myer L, Jaspan HB, Huang LC. The role of polyclonal intravenous immunoglobulin in treating HIV-infected children with severe bacterial infections: a retrospective cohort study. BMC Infect Dis 2008;8:127.

108. Office of AIDS Research (OAR) Advisory Council. Guidelines for the Prevention and Treatment of Opportunistic Infections in HIV-Exposed and HIV-Infected Children. J Pediatric Infect Dis Soc 2013;2(4):293-308.

109. Demirdjian G, Calle G, Gvirtzman C. Gammaglobulina su uso pediátrico basado en la evidencia científica. CIME 2006;9(38).

110. Esposito A, Mezzaroma I, Pastori D. Immunomodulatory effects of intravenous immunoglobulins (IVIGs) in HIV-1 disease: a systematic review. Int Rev Immunol 2011;30(1):44-66.

111. Eibl MM. History of Immunoglobulin Replacement. Immunol Allergy Clin N Am 2008;28(4):737-764.

112. Corbí AL, García FA, Domínguez-Soto A, Sánchez-Ramón S. Subcutaneous Immunoglobulins: A Promising Alternative for Immunomodulation? Current Pharmaceutical Design 2016;22(41):6300-6305.

113. Zhou TB, Su LN, Lei FY, Zhao YJ, Huang WF, Qin YH. The efficacy of different dose intravenous immunoglobulin in treating acute idiopathic thrombocytopenic purpura: a meta-analysis 
Espinosa-Rosales FJ et al. Inmunoglobulina G para reemplazo e inmunomodulación

of 13 randomized controlled trials. Blood Coag Fibrinolysis 2010;21(8):713-721.

114. Lilleyman JS, Eden OB. Guidelines for management of idiopathic thrombocytopenic purpura. The British Paediatric Haematology Group. Arch Dis Child 1992;67(8):1056-8.

115. Lim W, Crowther M, Cohen A, Solberg L, Crowther MA, Nuenert C. The American Society of Hematology 2011 evidencebased practice guideline for immune thrombocytopenia. Blood 2011;117(16):4190-207.

116. Del Vecchio GC, Russo G, De Santis A, Ramenghi U, Notarangelo L, De Mattia D. AIEOP-ITP Study Group-Management of chronic childhood immune thrombocytopenic purpura: AIEOP consensus guidelines. Acta Haematol 2010;123:96109.

117. Kiefel V, Mueller-Eckhardt C. High-dose IgG for post-transfusion purpura-revisited. Blut 1988;57(4):163-167.

118. Ali K, Blanchette V, Brouwers M, Couban S, Radmoor P, Anderson D. Guidelines on the Use of Intravenous Immune Globulin for Hematologic Conditions. Transfus Med Rev 2007;21(Suppl 1):S9-S56.

119. Lalezari P, Hilgartner M, Partin J, Fikrig S, O'Malley J, Bussel J. Reversal of neutropenia with intravenous gammaglobulin in autoimmune neutropenia of infancy. Blood 1983;62(2):398400.

120. Lalezari P, Fikrig S, Bussel J. Intravenous treatment with gamma-globulin of autoimmune neutropenia of infancy. J Pediatr 1988;112:298-301.

121. Behrens G, Jaeger G, Welte K, Bux J. Diagnosis and clinical course of autoimmune neutropenia in infancy: Analysis of 240 cases. Blood 1998;91(1):181-186

122. Kiwanuka J, Kadushin J, Gordon BG. Autoimmune neutropenia and Hodgkin's disease: Successful treatment with intravenous gammaglobulin. Am J Pediatr Hematol Oncol 1991;13:164-167.

123. Bussel J, Hilgartner MW. Use of intravenous gammaglobulin for the treatment of autoimmune neutropenia of childhood and autoimmune hemolytic anemia. Am J Med 1987;83:25-29.

124. Ventura A, Mascarin M. Anti-Rh(D) immunoglobulin for autoimmune neutropenia of infancy. Acta Paediatr 1993;82:142-144

125. Kallick MD, Sorensen RU. Clinical uses of intravenous immune globulin: immunoglobulin replacement therapy and treatment of autoimmune cytopenias. J Clin Apheresi 1988;4:97-103.

126. Barrios M, Tabuteau S, Desablens B, Alliot C. Autoimmune cytopenias associated with malignancies and succesfully treated with intravenous immune globulins: about two cases. Therapie 2000;55(3):371-374.

127. Fembracher PM, Schulz PC, Schoengen A. Immunoglobulin therapy for autoimmune neutropenia in Hodgkin's disease. Acta Haematol 1995;94:36-38.

128. Cunningham-Rundles C, Newland AC Flores G, Bussel JB. Efficacy of intravenous immunoglobulin in the treatment of autoimmune hemolytic anemia: results in 73 patients. Am J Hematol 1993;44(4):237-242.

129. Gordon PA, Winer JB, Hoogendijk JE, Choy EH. Immunosuppressant and immunomodulatory treatment for dermatomyositis and polymositis. Cochrane Database Syst Rev 2012;15(8):CD003643.

130. Sami N, Cafardi JM. Intravenous Immune Globulin in Amyopathic Dermatomyositis - Report of two cases and review of the literature. Open Rheumatol J 2015;4(9):77-81.

131. Shu XM, Tian XL, Chen F, Zu N, Ma L, Wang DX. Intravenous immunoglobulin therapy in adult patients with polymyositis/dermatomyositis: a systematic literature review. Clin Rheumatol 2012;31(5):801-806.

132. Alves SC, Isenberg DA, Fasano S. Current pharmacological treatment of idiopathic inflammatory myopathies. Expert Rev Clin Pharmacol 2016;1-12.

133. Lochmüller H, Toepfer M, Schlotter B, Reilich P, Schröder M, Walter MC. High-dose immunoglobulin therapy in sporadic inclusion body myositis: a double-blind, placebo controlled study. J Neurol 2000;247(1):22-8.

134. Rakocevic G, Joe G, Manoli L, Shrader J, Harris-Love M, Sparks S. Intravenous immune globulin in hereditary inclusion body myopathy: a pilot study. BMC Neurol 2007;29(7):3.

135. Sahrbacher U, Bremer J, Arndt B, Steiner U, Fontana A, Recher M. Treatment of inclusion body myositis: is low-dose intravenous immunoglobulin the solution? Rheumatol Int 2012;32(2):469-72.

136. Ducobu J, des Grottes JM, Cerny J, Delaunoit C, Capel P, Crenier L. Low response to high-dose intravenous immunoglobulin in the treatment of acquired factor VIII inhibitor. Br J Haematol 1996;95:750-753.

137. Waler ID, Lowe GDO, Tait RC, Dykes AC. Combined prednisolone and intravenous immunoglobulin treatment for acquired factor VIII inhibitors: A 2-year review. Haemophilia 2001;7:160-163.

138. Ningsanond V. Infection associated hemophagocytic syndrome: A report of 50 children. J Med Assoc Thai 2000;83:1141-1149.

139. Chang KC, Cheng CN, Tsai WH, Su IJ, Chen JS. Childhood hemophagocytic syndrome associated with Kikuchi's disease. Haematologica 2000;85(9):998-1000.

140. Buchanan GR, Fort DW. Treatment of infection associated hemophagocytic syndrome with immune globulin. J Pediatr 1994;124:332.

141. Rathore MH, Salman E, Joyce MJ, Pitel P, Freeman B. Intravenously administered immune globulin for the treatment of infection-associated hemophagocytic syndrome. J Pediatr 1993;123(3):479-481.

142. Seward D, Hatton C, Goulder P. Intravenous immunoglobulin in virus associated haemophagocytic syndrome. Arc Dis Child 1990;65:1275-1277.

143. Wong WW, Chiou TJ, Chen TL. Hemophagocytic syndrome: an unusual manifestation of acute human immunodeficiency virus infection. Int J Hematol 2003;78(5):450-452. 
144. Spencer A, Cobcroft RG, Gill DS. High-dose gammaglobulin therapy in the reactive haemophagocytic syndrome. $\mathrm{Br} J$ Haematol 1994;88:204-206.

145. Kuwabara S, Hatakeyama A, Fukutake T, Hattori T, Kaneko M. Guillain-Barre and virus associated hemophagocytic syndromes contracted simultaneously following EpsteinBarr viral infection. Neurology 1997;49(3):870-871.

146. Kawasaki T. Infantile acute febrile mucocutaneous lymph node syndrome with specific desquamation of the fingers and toes. Clinical observation of 50 cases. Jpn J Allerg 1967:78-222.

147. Naoe S. Kawasaki T. Hisotry of Kawasaki Disease. Clin Exp Nephrol 2014;18(2):301-304.

148. Furusho K. High-dose intravenous gamma globulin for Kawasaki disease. Lancet 1984;1055-1058.

149. Newburger JW. A Single Intravenous Infusion of Gamma Globulin as Compared with Four Infusions in the Treatment of Acute Kawasaki Syndrome. N Eng J Med 1991;324(23):1633-1639.

150. Research Committee of the Japanese Society of Pediatric Cardiology and Cardiac Surgery. Guidelines for medical treatment of acute Kawasaki disease: 2012 revised version. Pediatr Int 2014;56(2):135-158.

151. Lv HT, Sun L, Zhang JM, Cao L, Jia HL, Zhu BH. A metaanalysis on the effect of corticosteroid therapy in Kawasaki disease. Eur J Pediatr 2012;171(3):571-8.

152. Takahashi M, Gerber MA, Gewitz MH, Tany LY, Burns JC, Newburger JW. Diagnosis, treatment and long-term management of Kawasaki disease: a stetement for health professionals from the Committe on Rheumatic Fever, Endocarditis and Kawasaki Disease, Council on Cardiovascular Disease in the Young, American Heart Aassociation. Circulation 2004;110(17):2747-71.

153. Levin M, Shingadia D, Tulloh R, Klein NJ, Brogan PA, Eleftheriou D. Management of Kawasaki disease. Arch Dis Child 2014;99(1):74-83.

154. Burns JC, Baker A, Beiser AS, Newburger JW, Sundel RP. Gammaglobulin retreatment in Kawasaki disease. J Pediatr 1993;123:657-659.

155. Ohki H, Tsuchihashi T, Yamagishi H, Katada Y, Yamada $\mathrm{K}$, Miura M. Coronary risk factors in Kawasaki disease treated with additional gammaglobulin. Arch Dis Chidl 2004;89(8):776-780.

156. Wijdicks EF, Barohn R, Benson E, Cornblath DR, Hahn $A F$, Hughes RA. Practice parameter: immunotherapy for Guillain-Barré syndrome: report of the Quality Standars Subcommittee of the American Academy of Neurology. Neurology 2003;61(6):736-740.

157. Swan AV, Van Doorn PA, Hughes RA. Intravenous immunoglobulin for Guillain-Barré syndrome. Cochrane Database Syst Rev 2014;19(9):CDoo2063.

158. Apostolski S, Van Doorn P, Gilhus NE, Hietaharju A, Honkaniemi J, Elovaara I. EFNS guidlines for the use of intravenous immunoglobulin in treatment of neurological diseases. Eur J Neurol 2008;15(9):903-908.
159. Altamirano L, Amores M, Bertoti A, Cueto A, Diaz L, Figueredo $A$. Inmunoglobulina endovenosa en enfermedades neuromusculares guia para su utilización. Rev Neurol Arg 2006;31(1):32-46.

160. Drenthen J, Jacobs BC, Van Doorn PA, Dutch GBS Study Group, Ruts L. Distinguishing acute-onset CIDP from fluctuating Guillain-Barre syndrome: a prospective study. Neurology 2010;74(21):1680-6.

161. CENETEC. (2016) Guía de Práctica Clínica: Diagnóstico y tratamiento del Síndrome de Guillain-Barré en el segundo y tercer nivel de atención [en línea]. Dirección URL: <http:// www.cenetec.salud.gob.mx/descargas/gpc/CatalogoMaestro/089_GPC_SxGBarre2y3NA/GuillainBarrE_R_CENETEC. pdf $>$.

162. Chaudhry V, Katzberg H, Rae-Grant AD, So YT, Patwa HS. Evidence-based guideline: Intravenous immunoglobulin in the treatment of neuromuscular disorders: Report of the Therapeutics and Technology Assessment Subcommittee of the American Academy of Neurology. Neuroogy 2012;78(13):1009-1015.

163. Winer JB, Vermeulen M, de Haan R, van Schaik IN, Eftimov F. Intravenous immunoglobulin for chronic inflammatory demyelinating polyradiculoneuropathy. Cochrane Database Sys Rev 2013(12):CD001797.

164. Donofrio P, Bril V, Dalakas MC, Deng C, Hanna K, Hughes RA. Intravenous immune globulin (10\% caprylate-chromatography purified) for the treatment of chronic inflammatory demyelinating polyradiculoneuropathy (ICE study): a randomised placebo-controlled trial. Lancet 2008;7(2):136-4.

165. Join Task Force of the EFNS and the PNS. Guideline on management of chronic inflammatory demuelinating polyradiculoneuropathy. Report of a Joint Task Force of the European Federation of Neurological Societies and de Peripheral Nerve Society. J Peripher Nerv Syst 2005;10(3):220-8.

166. Hadden RD, Bouche P, Cornblath DR, Hahn A, Illa I, van den Bergh PY. European Federation of Neurological Societies / Peripheral Nerve Society guideline on management of chronic inflammatory demyelinating polyradiculoneuropathy. First revision. Eur J Neurol 2010;17(3):356-63.

167. Kes P, Zavoreo I, Lisak M, Zadro L, Coric L, Bascic-Kes V. Guidelines for the use of intravenous immunoglobulin in the treatment of neurologic diseases. Acta Clin Croat 2012;51(4):673-83.

168. Leger JM, Nobile-Orazio E, Cornblath DR, Hadden RD, Koski CL, van Schaik IN. Multifocal motor neuropathy. In: European Handbook of Neurological Management, $2^{\text {nd }}$ ed. United Kingdom: Wiley-Blackwell, 2012;(1):343-350.

169. Hughes RA, Nobile Orazio E, Léger JM, Umapathi T. Immunosuppressant and immunomodulatory treatments for multifocal motor neuropathy. Cochrane Database Syst Rev 2015(3):CD003217.

170. Van Schaik IN, Eftimov F. Immunotherapy of multifocal motor neuropathy. Expert Opin Biol Ther 2011;11(3):329-42.

171. Quarles RH, Farrer RG, Dambrosia J, Soueidan S, Stein DP, Dalakas MC. A controlled study of intravenous immunog- 
Espinosa-Rosales FJ et al. Inmunoglobulina G para reemplazo e inmunomodulación

lobulin in demyelinating neurpathy with IgM gammopathy. Ann Neurol 1996;40(5):792-795.

172. Roveri L, Swan A, Willison H, Bojar M, Illa I, Comi G. A randomised controlled trial of intravenous immunoglobulin in IgM paraprotein associated demyelinating neuropathy. J Neurol 2002;249(10):1370-1377.

173. Chastang C, Clavelou P, Louboutin JP, Leger JM, Brouet JC, Mariette $X$. A randomised clinical trial comparing interferon-a and intravenous immunoglobulin in polyneuropathy associated with monoclonal IgM. J Neurol Neurosurg Psychiatry 1997;63(1):28-34.

174. Nobile-Orazio E, Sommer C, Hahn AF, Illa I, Morra E, Hadden RD. Paraproteinaemic demyelinating neuropathies. In: European Handbook of Neurological Management, $2^{\text {nd }}$ ed. United Kingdom: Wiley-Blackwell, 2011;351-61.

175. Lunn MP, Nobile-Orazio E. Immunotherapy for IgM antimyelin-associated glycoprotein paraprotein-associated peripheral neuropathies. Cochrane Database Syst Rev 2006(2):CD002827.

176. Schonfeld T, Weitz R, Karmazyn B, Harel L, Straussberg R. Improvement of atypical acute disseminated encephalomyelitis with steroids and intravenous immunoglobulins. Pediatr Neurol 2001;24;139-43.

177. Ichiyama T, Hayasho T, Ouchi K, Furukawa S, Nishikawa M. Intravenous immunoglobulin therapy in acute disseminated encephalomyelitis. Pediatr Neurol 1999;21(2):583-6.

178. López-Marín L, López-Pino M, Gutiérrez-Solana G, SotoInsuga V, Cornejo-Moreno D, Rodríguez-Fernández C. Análisis de una serie de casos con diagnóstico inicial de encefalomielitis aguda diseminada en el período 2000-201. Rev Neurol 2013;57(7):297-305.

179. Ozkale O, Alkan O, Alehan F, Ilknur E. Acute Disseminated Encephalomyelitis in Child and Adolescents: A Single Center Experience. Pediatr Neurol 2016;49:266-73.

180. Di Pietro GM, Madini B, Mastrolia MV, Rigante D, Esposito S. A spectrum of inflammation and demyelination in acute disseminated encephalomielitis (ADEM) of children. Autoimmun Rev 2015;14(10):923-9.

181. Wong AH, Quek AM, Yuki N, Viswanathan S. Intravenous immunoglobulin may reduce relapse frequency in neuromyelitis optica. J Neuroimmunol 2015;15(282):92-6.

182. Panicker J, Mutch K, Boggild M, Appleton R, Jacob A, Elsone L. Role of intravenous immunoglobulin in the treatment of acute relapses of neuromyelitis optica: experience in 10 patients. Mult Scler 2014;20(4):501-4.

183. Conte M, Biacncheri R, Acquaviva A, De Bernardini B, Edvige V. Effect of Steroid and High Dose Immunoglobulin Therapy on Opsoclonus Myoclonus Syndrome Occuring in Neuroblastoma. Medical Pediatric Oncology 1998;30:15-17.

184. Sugie $Y$, Akimoto $H$, Endo $K$, Shirai $M$, Ito $M$, Sugie $H$. High dose IV human immunoglobulin in a case with infanitle opsoclonus polymyoclonia syndrome. Acta Paediatr 1992;81:371-2.

185. Weemaes C, Verbeek M, Willemsen M, Rotteveet J, Leen WG. Rituximab and intravenous immunoglobulins for realpsing postinfectious opsoclonus myoclonus syndrome. Pediatr Neurol 2008;39:213-17.
186. Allison T, Pranzantelli M, Verhulst S, Tate ED. Neuroepidemiologic Trends in 105 US Cases of Pediatric Opsoclonus-Myoclonus Syndrome, J Pediatr Oncol Nurs 2005;22(1):8-19.

187. Dalakas MC. The role of IVIG in the treatment of patients with stiff person syndrome and other neurological diseases associated with anti-GAD antibodies. J Neurol 2005;252(1):119-25.

188. Fuji M, Li M, Lufti B, Kyhos J, McElroy B, Dalakas MC. High-dose intravenous immune globulin for stiff-person syndrome. N Eng J Med 2001;345(26):1870-6.

189. Zivkovi S. Intravenous immunoglobulin in the treatment of neurologic disorders. Acta Neurol Scand 2015. Doi: 10.1111/ane.12444.

190. Kleopa KA, Wu GF, Rossi JE, Rosenfeld MR, Dalmau J, Bataller L. Autoimmune limbic encephalitis in 39 patients: immunphenotypes and outcomes. J Neurol Neurosurg Psychiatry 2007;78(4):381-385.

191. Petit-Pedrol M, Dalmau J, Armangue T. Autoimmune encephalitis in children. J Child Neurol 2012;27(11):14601469.

192. Leypoldt F, Armangue T, Dalmau J. Autoimmune encephalopathies. Ann N Y Acad Sci 2015;1338:94-114.

193. Chevret S, Toyka KV, Gajdos P. Intravenous immunoglobulin for myasthenia gravis. Cochrane Database Syst Rev 2012(12):.

194. CENETEC (2010). Guía de Práctica Clínica: Tratamiento de la Miastenia Gravis en el Adulto. [en línea]. Dirección URL: <http://www.cenetec.salud.gob.mx/descargas/ gpc/CatalogoMaestro/391_IMSS_10_Miastenia_Gravis/ EyR_IMSS_391_10.pdf>.

195. Chevret S, Gajdos P. Treatment of myasthenia gravis acute exacerbations with intravenous immunoglobulin. Ann NY Acad Sci 2008;1132:271-5.

196. Barohn RJ, Dubinsky R, Miller RG. Expanding the evidence base for therapeutics in mysthenia gravis. Ann neurol 2010;68(6):776-7.

197. Maddison P, Newsom-Davis J. Treatment for LambertEaton myathenic syndrome. Cochrane Database Syst Rev 2005(2):CD003279.

198. Motomura M, Newsom-Davis J, Misbah SA, Chapel HM, Vincent A, Bain PG. Effects of intravenous immunoglobulin on muscle weakness and calcium-channel autoantibodies in the Lambert-Eaton myasthenic syndrome. Neurology 1996;47(3):678-683.

199. Renier WO, Weemaes CM, Gabreels FJ, Meinardi H, van Engelen BG. Immunoglobulin treatment in epilepsy, a review of the literature. Epilepsy Res 1994;19(3):181-90.

200. Baskin E, Dener S, Gültein A, Tanzer F, Sekreter E, Türkay S. Immune globulin treatment in intractable epilepsy of childooh. Turk J Pediatr 1996;38(3):301-305.

201. Avanzini G, Villani F. The use of immunoglobulins in the treatment of human epilepsy. Neurol Sci 2002;23(1):33-37.

202. Reiner WO, Weemaes CM, van Engelen BG. Immunoglobulin treatment in human and experimental epilepsy. Neurol Sci 2002;23(1):33-37. 
203. Shalev RS, Kazir E, Engelhard D, Amir N, Gross-Tsur V. Inravenous high-dose gammaglobulins for intractable childhood epilepsy. J Neurol Neurosurg Psychiatry 1994;57:72-5.

204. Shalev RS, Kazir E, Engelhard D, Amir N, Gross-Tsur V. Intravenous high-dose gammaglobulins for intractable childhood epilepsy. Acta Neurol Scand 1993;88(3):204-9.

205. Levinson Al. The use of IVIG in neurological disease. Clin Rev allergy 1992;10(1-2):119-134.

206. Jaffe M, Pollack, Zelnik N, Benderly A, Tal Y, Etzioni A. High dose intravenous gammaglobulin in intractable epilepsy of childhood. Eur J Pediatr 1991;150(9):681-683.

207. Grupo de trabajo de la Guía de práctica clínica sobre la atención a las personas con eslcerosis múltiple. AIAQS y FEM/Cemcat. (2012) Guía de práctica clínica sobre la atención a las personas con eslcerosis múltiple. [en línea]. Dirección URL: <https://www.cem-cat.org/sites/default/ files/guia-practica-clinica.pdf>.

208. Gray O, McDonnell GV, Forbes RB. Intravenous immunoglobulins for multiple sclerosis. Cochrane Database Syst Rev 2003(4):CD002936.

209. Bryant J, Milne R, Clegg A. Disease-modifying drugs for multiple sclerosis: a rapid and systematic review (Structured abstract) Centre for Reviews and Dissemination. Health Technology Assessment 2000;4(9):1-101.

210. National Institute for Health and Care Excellence. (2014) Multiple sclerosis in adults: management. NICE Guidelines. Onlin[en línea]. Dirección URL: <https://www.nice.org.uk/ guidance/cg186\#>.

211. Frohman EM, Garmany GP Jr, Halper J, Likosky WH, Lublin FD, Gooding DS. Disease modifying therapies in multiple sclerosis: report of the Therapeutics and Technology Assessment Subcommittee of the American Academy of Neurology and the MS Council for Clinical Practice Guidelines. Neurology 2002;58(2):169-78.

212. Barnett MH, Boggild M, Brew BJ, Butzkueven $H$, Heard R, Broadley SA. Therapeutic approaches to disease modifying therapy for multiple sclerosis in adults: an Australina and New Zealand perspective: part 2, new and emergin therapies and their efficacy. J Clin Neurosci 2014;21(11):18471857.

213. Multiple Sclerosis Therapy Consensus Group (MSTCG). Basic and escalating immunomodulatory treatments in multiple sclerosis: current therapeutic recommendations. J Neurol 2008;255(10):1449-63.

214. Hutton B, Sharma M, Timmouth A, Wilson K, Cameron $D W$, Fergusson $D$. Use of intravenous immunoglobulin for treatment of neurologic conditions: a systematic review. Transfusion 2005;45(10):1640-1657.

215. Rabinstein A, Cree B, Dubinsky R, Day G, Haboubi M, Rae-Grant A. Disease-modifying therapies for multiple sclerosis. A guideline project protocol. Proposal of the Guideline Development, Dissemination and Implementation Subcommittee of the American Academy of Neurology. Neurology 2015:1-18.
216. Ramiro S, Gaujoux-Viala C, Takase K, Leon-Garcia M, Emery $P$, Nam JL. Efficacy of bioloical disease-modifying antirheumatic drugs: a systematic literature review informing the 2013 update of the EULAR recommendations for the management of rheumatoid arthritis. Ann Rheum Dis 2014;73(3):516-28.

217. Weiss PF, Beukelman T, DeWitt EM, llowite NT, Kimura Y, Ringold S. 2013 update of the 2011 American College of Rheumatology recommendations for the treatment of juvenile idiopathic arthritis: recommendatios for the medical therapy of children with systemic juvenile idiopathic arhtritis and tuberculosis screening. Arthritis Rheum 2013;65(10):2499-2512.

218. Khattri S, Zandman-Goddard G, Katz-Agranov N. The role of intravenous immunoglobulins in the treatment of rheumatoid arthritis. Autoimmun Rev 2015;14(8):651-8.

219. NHS England Clinical Reference Group for Paediatric Medicine. (2015) Biologic Therapies for the treatment of Juvenile Idiopathic Arthritis. [en línea]. Dirección URL: $<$ https://www.engage.england.nhs.uk/consultation/ specialised-services-policies/user_uploads/biolgcs-juvenlidiop-arthrs-pol.pdf>

220. Laxer RM, Hashkes PJ. Management of juvenile idiopathic arthritis. JAMA 2005;294:1671-1684.

221. Merrill JT. Treatment of systemic lupus erythematosus: a 2012 update. Bull NYU Hosp Jt Dis 2012;70(3):172-6.

222. Tektonidou M, Amoura Z, Aringer M, Bajema I, Berden JH, Bertsias GK. Joint European League Against Rheumatism and European Renal Association-european Dyalisys and Transplant Association (EULAR/ERA-EDTA) recommendations for the management of adult and paediatric lupus nephritis. Ann Rheum Dis 2012;71(11):1771-1782.

223. D'Cruz D, Sakthiswary R. Intravenous Immunoglobulin in the Therapeutic Armamentarium of Systemic Lupus Erythematosus: A systematic Review and Meta-Analysis. Medicine (Baltimore) 2014;93(16):e86.

224. Singh-Grewal D, Kim S, Craig JC, Tong A, Ttunnicliffe DJ. Diagnosis, Monitoring, and Treatment of Systemic Lupus Erythematosus: A Systematic Review of Clinical Practice Guidelines. Arhtritis Care Res (Hoboken) 2015;67(10):1440-52.

225. van Vollenhoven RF, Bernatsky SR, Smith CD, Hudson M, Inanc M, Muangchan C. Tretment algorithsm in Systemic Lupus Erythematosus. Arhtritis Care Res (Hoboken) 2015;67(9):1237-1245.

226. Cheleschi S, Guidelli GM, Galeazzi M, Fioravanti A, Tenti S. Intravenous immunoglobulins and antiphospholipid syndrome: How, when and why? a review of the literature. Autoimmun Rev 2016;15(3):226-35.

227. Mariotti P, Manna R, Brogna C. Conventional and intravenous immunoglobulin therapy in paediatric antiphospholipid antibodies-related chorea. Lupus 2014;23(14):1449-51.

228. Luqmani RA. State of the art in the treatment of systemic vasculitides. Front Immunol 2014;5:471.

229. Villa-Forte A. European Leauge Against Rheumatism/ European Vasculitis Study Group recommendations for 
Espinosa-Rosales FJ et al. Inmunoglobulina G para reemplazo e inmunomodulación

the management of vasculitis. Curr Opin Rheumatol 2010;22(1):49-53.

230. Anton J, Lahdenne P, Quartier P, Ravelli A, Wulffraat NM, Boom V. Evidence-based diagnossis and treatment of macrophage activation syndrome in systemic juvenile idiopathic arthritis. Pediatr Rheumatol Online J 2015;13(1):55.

231. Davi S, Minoia F, Ravelli A, Cron RQ. Clinical features and correct diagnosis of macrophage activation syndrome. Expert Rev Clin Immunol 2015;11(9):1043-53.

232. Batu ED, Ünal $S$, Bilginer $Y$, Cetin $M$, Tuncer $M$, Aytac $S$, et al. Macrophage activation syndrome in children with systemic juvenile idiopathic arthritis and systemic lupus erythematosus. Rheuumatol Int 2016;36(10):1421-9.

233. Palda VA, Meyer RM, Blydt-Hanser TD, Campbell P, Cardella $C$, Shehata N. The use of immunoglobulin therapy for patients undergoing solid organ transplantation: an evidence-based practice guideline. Trans Med Rev 2010;24(Suppl 1):S7-27.

234. Tyan D, Stablein D, McIntosh M, Rose S, Vo A, Jordan SC. Evaluation of intravenous immunoglobulin as an agent to lower allosensitization and improve transplantation in highly sensitized adult patients with end-stage renal disease. Report of the NIH IG02 trial. J Am Soc Nephrol 2004;15:3256-3262.

235. Vo A, Tyan D, Toyota M, Jordan SC. Desensitization therapy with intravenous gammaglobulin (IVIG): applications in solid organ transplantation. Trans Am Clin Climatol Assoc 2006;117:199-211.

236. Akposso K, Haymann KP, Flahaut A, Marlin C, Rondear E, Peraldi MN. Long-term benefit of intravenous immunoglobulins in cadaveric kidney retransplantation. Transplantation 1996;62(11):1670-1673.

237. del Crial M, Opelz G, Goldberg JC, Argento JA, Guardia $\mathrm{OE}$, Casadei $\mathrm{DH}$. A randomized and prospective study comparing treatment with high-dose intravenous immunoglobulin with monoclonal antibodies for rescue of kidney grafts with steroid-resistant rejeection. Transplantation 2001;71(1):53-58.

238. Scarisbrick JJ, Cornish J, Clark A, Amrolia P, Jackson G, Dignan FL. Organ-specific mangamente and supportive care in chronic graft-versus-host disease. $\mathrm{Br} \mathrm{J}$ Haematol 2012;158(1):62-78.

239. Antin JH, Wolff SN, Bierer BE, Small T, Miller KB, Winston DJ. A multicenter, randomized, double-blind comparison of different doses of intravenous immunoglobulin for prevention of graft-versus-host disease and infection after allogeneic bone marrow transplantation. Bone Marrow Transplant 2001;28(2):187-96.

240. Storek J, Kopecky KJ, Jocom J, Longton G, Flowers M, SuIlivan KM. A controlled trial of long-term administration of intravenous immunoglobulin to prevent late infection and chronic graft-vs-host disease after marrow transplantation: clinical oucome and effect on subsequent immune recovery. Bioll Blood Marrow Trasnplant 1996;2(1):44-53.

241. Berger M, Lazarus HM, Sokos DR. Intravenous immunoglobulin: appropiate indications and uses in hematopoietic stem cell transplantation. Biol Blood Marrow Transplant 2002;8(3):117-130.

242. Zuckerman M, Jackson G, Aitken C, Osman H, Pagliuca A, Emery $\mathrm{V}$. Management of cytomegalovirus infection in haematopoietic stem cell transplantation. $\mathrm{Br} J$ Haematol 2013;162(1):25-39.

243. Grupo Español de Medicamentos hemoderivados y la Sociedad Española de Farmacia Hospitalaria (2013). Guía clínica para el uso de inmunoglobulinas [en línea]. Dirección URL: <https://www.sefh.es/bibliotecavirtual/ Guia_Igb/Guia_Imnunoglobulinas.pdf $>$.

244. Alfieri C, Preiksaitis J, Humar A, Moore D, Tapiero B, Allen $U$. Epstein-Barr virus infection in transplant recipients: summary of a workshop on surveillance, prevention and treatment. Can J Infect Dis 2002;13:89-99.

245. Gafter-Gvili A, Paul M, Ben-Bassat I, Leibovici L, Shpilberg $\mathrm{O}$, Raanani P. Immunoglobulin prophylaxis in hematological malignancies and hematopoietic stem cell transplantation. Cochrane Database Syst Rev 2008;8(4):CD006501.

246. Gafter-Gvili A, Paul M. Ben-Bassat I, Leibovici K, Shpilberg $\mathrm{O}$, Raanani P. Immunoglobulin prophylaxis in hematopoietic stem cell transplantation: systematic review and metaanalysis. J Clin Oncol 2009;27(5):770-781.

247. Chiller T, Einsele H, Gress R, Sepkowitz K, Stoerk J, Tomblyn $M$. Guidelines for preventing infectious complications among hematopoietic cell transplantation recipients: a global perspective. Biol Blood Marrow Transplant 2009;15(10):1143-238.

248. French Hutchinson Cancer Research Center, Seattle Cancer Care Alliance (2015). Long-Term Follow up after Hematopoietic stem cell transplant. General Guidelines for referring physicians. [en línea]. Dirección URL: <https://www. fredhutch.org/content/dam/public/Treatment-Suport/ Long-Term-Follow-Up/LTFU_HSCT_guidelines_physicians. pdf $>$.

249. Kopecky KJ, Jocom J, Fisher L, Bucnker CD, Meyers JD, SuIlivan KM. Immunomodulatory and antimicrobial efficacy of intravenous immunoglobulin in bone marrow transplantation. N Eng J Med 1990;323:702-12.

250. Graham Pole J, Del Rosario ML, Longmate J, Ochoa S, Amylon M, Abel-Mageed A. Comparison of two doses of intravenous immunoglobulin after allogeneic bone marrow transplants. Bone Marrow Transplant 1999;23(9):929-932.

251. Lansang MAD, Dans LF, Mantaring JB, Alejandria MM. Intravenous immunoglobulin for treating sepsis, severe sepsis and septic shock. Cochrane Database Syst Rev 2013(9):CD001090.

252. Gotzsche PC, Pildal J. Polyclonal immunoglobulin for treatment of bacterial sepsis: a systematic review. Clin Infect Dis 2004;39:38-46.

253. Darenberg J, Sjölin J, Henriques-Normark B, Norrby-Teglund A, Linnér A. Clinical Efficacy of Polyspecific Intravenous Immunoglobulin Therapy in Patients with Streptococcal Toxic Shock Syndrome: A Comparative Observational Study. Clin Infect Dis 2014;59(6):851-857. 
254. Orange J, Wahn V. Clinical use of immunoglobulins, in Clinical use of immunoglobulins. Germany: UNI-MED Science, 2013.

255. Department of Health. (2012, March) NHS Scotland Clinical Guidelines for Immunoglobulin Use. [en línea]. Dirección URL: <http://www.nsd.scot.nhs.uk/Documents/clinimmumoMarch12.pdf>.

256. Keates S, Pothoulakis C, Warny M, Castagliuolo I, LaMont JT, Salcedo J. Intravenous immunoglobulin therapy for severe Clostridium difficile colitis. Gut 1997;41(3):366-70.

257. Broor A, Cui W, Jaar BG, Abougergi MS. Intravenouss immunoglobulin for the treatment of severe Clostridium difficile colitis: An observational study and review of the literature. J Hosp Med 2010;5:E1-9.

258. Shaaban H, Spira R, Slim J, Boghossian J, Shah N. Intravenous immunoglobulin in the treatment of severe Clostridium difficile colitis. J Glob Infect Dis 2014;6(2):82-85.

259. Koirala J, Shahani L. Intravenous immunoglobulin in treatment of Clostridium difficile colitis. BMJ Case Rep 2012.

260. Terrier B, Rozenberg F, Pestre V, Legendre C, Hermine O, Crabol Y. Intravenous immunoglobulin therapy for pure red cell aplasia related to human parvovurs b19 infection: a retrospective study of 10 ptients and review of the literature. Clin Infect Dis 2013;56(7), pp. 968-977, 2013.

261. INIS Collaborative Group. Treatment of neonatal sepsis with intravenous immune globulin. N Eng J Med 2001;365(13):1201-1211.

262. Ohlsson A, Lacy JB. Intravenous immunoglobulin for suspected or proven infections in neonates. Cochrane Database Syst Rev 2015(3):CD001239.

263. Lacy JB, Ohlsson A. Intravenous immunoglobulin for preventing infection in preterm and/or low birth weight infants. Cochrane Database Syst Rev 2013;2(7).

264. Berkowitz RL, Lembet AA, Lapinski R, McFarland JG, Bussel JB, Gaddipati S. Initial fetal platelet counts predict the response ot intravenous gammaglobulin therapy in fetuses that are affected by PLA1 incompatibility. Am J Obstet Gynecol 2001;185(4):976-980.

265. Kaplan C, Bertrand G. How do we treat fetal and neonatal alloimune thrombocytopenia. Transfusion 2014;54:16981703.

266. Murphy MF, Kroll H, Waters AH, Kaplan C. Feto-maternal alloimmune thrombocytopenia: antenatal therapy with IVIG and steroids-more questions than answers. $\mathrm{Br} J$ Haematol 1998;100(1):62-65.

267. Hoch J, Bauer H, Bald R, Kiefel V, Kroll H, Giers G. Therapy with intravenous immunoglobulin $\mathrm{G}$ (IVIG) during pregnancy for fetal alloimmune HPA-1a (Zwa) thrombocytopenic purpura. Prenat Diagn 1996;16(6):495-502.

268. Porter TF, Branch DW, Esplin MS, Scott JR, Silver RM. Neonatal alloimmune thrombocytopenia: Antenatal management. Am J Obstet Gynecol 2000;182(5):1233-1238.

269. Wilson RD, Ballem P, Wittmann BK, Farguharson DF, Kornfeld I. Antenatal invasive and non-invasive management of alloimmune thrombocytopenia. Fetal Diagn Ther 1996;182(5):1233-1238
270. Berkowitz RL, Lynch L, Lesser ML, Paidas MJ, Huang CL, Bussel JB. Antenatal management of alloimmune thrombocytopenia with intravenous gamma-globulin: a randomized trial of the addition of low-dose steroid to intravenous gammagglobulin. Am J Obstet Gynecol 1996;122(2):1414-1423.

271. Murphy MF, Kalpan C, Kroll H, Birchall JE. European coIlaborative study of the antenatal management of fetomaternal alloimmune thrombocytopenia. $\mathrm{Br} J$ Haematol 2003;122(2):275-288

272. Hirfanoglu I, Turkyilmaz C, Altuntas N, Unal S, Turan O, Beken S. Intravenous immunoglobulin $\mathrm{G}$ treatment in $\mathrm{ABO}$ hemolytic disease of the newborn, is it myth or real? Indian J Hematol Blood Transfus 2014;30(1):12-15.

273. Rodríguez-Miguélez JM, Iriondo-Sanz M, Salvia Roiges MD, Botet-Mussons F, Carbonell-Estrany X, Figueras-Aloy $J$. Intravenous immunoglobulin and necrotizing enterocolitis in newborns with hemolytic disease. Pediatrics 2010;125(1):139-144.

274. Legnani E, Galletti S, Arcuri S, Aceti A, Faldella G, Corvaglia L. Intravenous immunoglobulin to treat neonatal alloimmune haemolytic disease. J Matern Fetal Neonatal Med 2012;12:2782-2785.

275. Ramos-Caro FA, Flowers FP, Fromowtiz JS. Practical Guidelines for the management of toxi epidermal necrolysis and Stevens-Johnson syndrome. Int J Dermatol 2007;46(10):1092-1094.

276. Del Vecchio MT, Aronoff SC, Barron SJ. Intravenous immunoglobulin in the treatment of Stevens-Johnson syndrome and toxic epidermal necrolysis: a meta-analysis with meta-regression of observational studies. Int J Dermatol 2015;54(1):108-115.

277. Li YC, Chen TJ, Huang YC. The efficacy of intravenous immunoglobulin for the treatment of toxic epidermal necroIysis: a systematic review and meta-analysis. $\mathrm{Br} J$ Dermatol 2012;167(2):424-432.

278. Taghipour K, Mohd Mustapa MF, Highet AS, Kirtschig G, Venning VA. British Association of Dermatologists guidelines for the management of bullous pemphigoid. Br J Dermatol 2012;167,(6):1200-14.

279. European Dermatology Forum Guideline Subcommittee. Guidelines on the use of high-dose intravenous immunoglobulin in dermatology. Eur J Dermatol 2009;19(1):908.

280. Takashima S, Yhoshida S, Dougu N, Inoue H, Tanaka K, Taguchi Y. Psoriasis improved by intravenous immunoglobulin therapy. Int Med 2006;45(14):879-880.

281. Mediwake R, Fernando M, Whittaker S, Rustin MH, Beynon $\mathrm{HL}$, Gurmin V. Psoriasis: response to high-dose intravenous immunoglobulin in three patients. $\mathrm{Br} J$ Dermatol 2002;147(3):554-557.

282. Hughes J, Jolles S. Use of IGIV in the treatment of atopic dermatitis, urticaria, scleromyxedema, pyoderma gangrenosum, psoriasis and pretibial myxedema. Int Immunopharmacol 2006;6(4):579-91.

283. Kim JH, Baek HS, Lee HB, Oh JW, Jee SJ. Long-term Efficacy of Intravenous Immunoglobulin Therapy for Moderate 
Espinosa-Rosales FJ et al. Inmunoglobulina G para reemplazo e inmunomodulación

to Severe Childhood Atopic Dermatitis. Allergy Asthma Immunol Res 2011;3(2):89-95.

284. Kim BJ, Park Y, Lee SY, Kim WK, Kim JE, Park JS. KAAACI Work Group on Severe/Recalcitratn Atopic Dermatitis. Korean J Asthma Allergy Clin Immunol 2010;30:255-270.

285. Kim KE, Sohn MH. Use of intravenous immunoglobulin in the treatment of childhood atopic dermatitis. Allergy Asthma Immunol Res 2011;3(2):65-6.

286. Jolles S. A review of high-dose intravenous immunoglobulin treatment for atopic dermatitis. Clin Exp Dermatol 2002;27(1):3-7.

287. Salt AT, Crowe BH. Autism: the management and support of children and young people on the autism spectrum. NICE Clinical Guideline 170. Arch Dis Child Educ Pract Ed 2015;100(1):20-23.

288. Ferrari-Arroyo MJ, Boada-Muñoz L, Touriño-Aguilera E, Artigas-Pallarés J, Belinchón-Carmona M, Fuentes-Biggi J. Good practice guidlines for the treatment of autistic spectrum disorders. Rev Neurol 2006;43(7):425-38.

289. Simon L, Schmeidler J, Cunningham-Rundles C, Hollander E, Del Giudice-Asch G. Brief report: a pilot open clinical trial of intravenous immunoglobulin in childhood autism. J Autism Dev Disord 1999;29(2):157-160.

290. Samra D, Agrawal S, Gupta S. Adaptive and Innate Immune REsponses in Autism: Rationale for Therapeutic Use of Intravenous Immunoglobulin. J Clin Immunol 2010;30(Suppl 1):S90-96.

291. United Health Care (2017). Immune Globulin (IVIG AND IGSC) [en línea]. DirecciónURL: <https://www.unitedhealthcareonline.com/ccmcontent/ProviderlI/UHC/ en-US/Assets/ProviderStaticFiles/ProviderStaticFilesPdf/ Tools\%20and\%20Resources/Policies\%20and\%20Protocols/ Medical\%20Policies/Drug\%20Policies/IVIG_policy.pdf>.

292. Leonard HL, Rapoport JL, Swedo SE. The pediatric autoimmune neuropssychiatric disorders associated with streptococcal infection (PANDAS) subgroup: separating fact from fiction. Pediatrics 2004;113(4):907-11.

293. Hickie I, Hadzi-Pavlovic D, Tymms K, Wakefield D, Dwyer J, lloyd A, Vollmer-Conna U. Intravenous immunoglobulin is ineffective in the treatment of patients with chronic fatigue syndrome. Am J Med 1997;103(1):38-43.

294. Shepard J, Macres M, Schenck C, Crosson J, Rechtman D, Peterson PK. A controlled trial of intravenous immunoglobulin $\mathrm{G}$ in chronic fatigue syndrome. Am J Med 1990;89(5):554-560.

295. Hickie I, Wakefiled D, Boughton C, Dwyer J, Lloyd A. A double-blind, placebo-controlled trial of intravenous immunoglobulin therapy in patients with chronic fatigue syndrome. Am J Med 1990;89(5):561-568.

296. Bonvicini F, Gelsomino F, Manfredi R, Cascavilla A, Viale P, Attard L. Paradoxical response to intravenous immunoglobulin in a case of Parvovirus B19-associated chronic fatigue syndrome. J Clin Virol 2015;62:54-57.

297. Mohan U, Bush A, Rosenthal M, Balfour-Lynn IM. Intravenous immunoglobulin for cystic fibrosis lung disease: a case series of 16 children. Arch Dis Child 2004;89(4):315-9.

298. Pankuweit S, Maisch B. Standard and etiology-directed evidence-based therapies in myocarditis: state of the art and future perspectives. Heart Fail Rev 2013;18(6):761-795.

299. Hartling L, Vandermeer B, Klassen TP, Robinson J. Intravenous immunoglobulin for presumed viral myocarditis in children and adults. Cochrane Database Syst Rev 2015(1):CD004370.

300. Tan SL, Shehata F, Holzer H, bucket W, Ata B. A systematic review of intravenous immunoglobulin for treatment of unexplained recurrent miscarriage. Fertil Steril 2011;95(3):1080-5e1-2.

301. Kutteh WH, Purkiss S, Librach C, Shultz P, Houlihan E, Liao $C$, Stephenson MD. Intravenous immunoglobulin and idiopathic secondary recurrent miscarriage: a multicentered randomized placebo-controlled trial. Hum Reprod 2010;25(9):2203-9. 